\title{
UN MODELO CcP DEL MERCADO DE VALORES
}

\author{
Shimshon Bichler* \\ Jonathan Nitzan**
}

$\mathrm{E}$ ste artículo esboza un modelo del mercado de valores basado en el capital como poder ( $\mathrm{CcP}$ ). Dicho modelo es necesario por dos razones. Primera, el mercado de valores es hoy la brújula principal del modo capitalista de poder. Segunda, hasta ahora no hemos desarrollado una teoría del $\mathrm{CCP}$ para describirlo ${ }^{1}$.

Por sorprendente que parezca, toda modelación del mercado de valores a largo plazo se deriva de un metadogma único que llamamos “tesis del desajuste"(Bichler y Nitzan, 2009; 2015a). Su premisa básica es la bifurcación general entre economía y política (una abreviatura de los ámbitos no económicos de la sociedad) y la división adicional, dentro de la economía, entre las esferas "real" y "nominal". En este dogma, las finanzas son un espejo nominal simbólico que refleja la economía real, pero ese reflejo es imperfecto, y este es aquí el punto

* Profesor de Economía Política en varias universidades de Israel, tookie@barak. net.il].

** Profesor de Economía Política, Universidad de York, Canadá, [nitzan@yorku. ca]. Este artículo se presentó en la cuarta conferencia $\mathrm{CcP}_{\mathrm{c}}$ " $\mathrm{El}$ capital como poder: ampliando la visión”, Universidad de York, 28-30 de septiembre de 2016. Todas las publicaciones de los autores, de acceso gratuito, se encuentran en The Bichler \& Nitzan Archives [http://bnarchives.net]. El trabajo para este escrito fue apoyado en parte por el sshrc. Traducción de Alberto Supelano. Fecha de recepción: 5-10-2016, fecha de revisión: 15-04-2017, fecha de aceptación: 2704-2017. Sugerencia de citación: Bichler, S. y J. Nitzan. "Un modelo CcP del mercado de valores", Revista de Economía Institucional 19, 36, 2017, pp. 11-56. DOI: https://doi.org/10.18601/01245996.v19n36.02

${ }^{1}$ La teoría del capital como poder plantea que el capitalismo se entiende mejor como un modo de poder y no como un modo de producción y consumo, y que el capital no es tiempo de trabajo ni máquinas sino la institución central del poder en el capitalismo. Para lectores legos Nitzan y Bichler (2012b) ofrecen un breve resumen del CcP, Nitzan y Bichler (2009a) hacen una exposición más amplia y Nitzan y Bichler (2015c) reúnen una serie de artículos recientes. Bichler y Nitzan (2015b) describen el pasado, el presente y el futuro del proyecto CcP, incluida una extensa bibliografía. 
clave. Las magnitudes financieras tienden a desajustarse de la realidad, y el propósito del modelo es explicar este desajuste y predecir sus consecuencias ${ }^{2}$.

Nuestro modelo CcP no empieza negando esos resultados y predicciones convencionales, sino interpretándolos de manera muy diferente. El modelo sugiere que bajo la apariencia económica de la tesis del desajuste existe un proceso de poder, y que este $-\mathrm{y}$ no la productividad ni la utilidad económica- es el que guía el mercado de valores. Esta interpretación alternativa es importante por tres razones: primera, suscita preguntas que las teorías convencionales no pueden hacer; segunda, lleva a resultados que contradicen algunos supuestos básicos de la economía política tradicional y heterodoxa; y, tercera, podría abrir la puerta para una mejor comprensión del modo capitalista de poder y de cómo oponerse a él y transformarlo.

El artículo consta de siete secciones. La discusión sustantiva empieza en la primera sección, con una rápida ojeada a las alzas y bajas del mercado bursátil en los dos últimos siglos; esta sección identifica algunos patrones cuantitativos del mercado, con las transformaciones cualitativas del poder subyacentes. La segunda sección explica la tesis del desajuste, mientras que la tercera sección describe el modelo de valoración de John Hussman, presidente de Hussman Investment Trust, que hasta donde sabemos hace las mejores predicciones de los rendimientos de largo plazo del mercado de valores. El resto del artículo describe nuestro modelo, ilustrado por el triángulo de Penrose.

Triángulo de Penrose

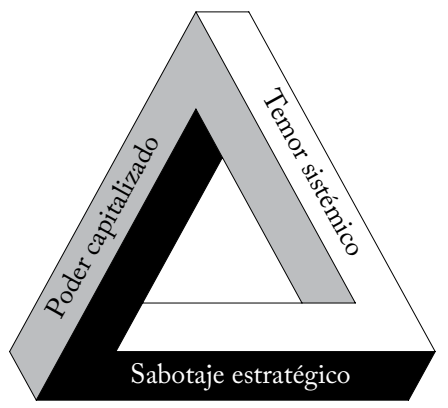

\footnotetext{
${ }^{2}$ Es cierto que muchos modelos prácticos de inversión -como los que se basan en el momento, el análisis cuantitativo y el seguimiento de índices, entre otros rituales- no se apoyan directamente en la valoración de los fundamentos económicos. Pero todos ellos suponen que, en último análisis, la capitalización refleja y debe converger hacia ellos. Para los manuales sobre valoración de mayor venta, ver Damodaran $(2011,2012)$ y McKinsey \& Co. et al. (2011).
} 
Así, la cuarta sección muestra que los resultados de Hussman se pueden reproducir considerando directamente el poder capitalizado y no la economía utilitaria de producción y consumo. La quinta sección explora cómo se entrelaza el poder capitalizado con lo que llamamos temor sistémico. La sexta sección sugiere que la fuerza motriz del poder capitalizado y del temor sistémico es lo que Thorstein Veblen llamó sabotaje estratégico, y especula acerca del modo en que la política económica se ha integrado al mercado de valores guiado por el CcP. La última sección concluye con un breve resumen y algunas reflexiones sobre el futuro.

Antes de pasar a nuestro argumento, debemos señalar que los principios que tratamos aquí son generales, pero el análisis empírico se limita a Estados Unidos. Debido a esta limitación, el artículo es explorativo y tentativo, no exhaustivo y definitivo.

\section{PRINCIPALES MERCADOS BAJISTAS}

Empecemos con la gráfica 1, que muestra los precios anuales de las acciones en Estados Unidos desde finales del siglo xviII. El panel superior muestra los niveles y el panel inferior muestra las tasas de cambio. Los precios se expresan en "dólares constantes", es decir, en cada año el índice del precio nominal se divide por el IPC.

\section{¿Poder adquisitivo o poder diferencial?}

Los economistas hacen esta transformación para mostrar los precios de las acciones en lo que llaman "términos reales". Y lo que entienden por "términos reales" es aquí poder adquisitivo". Según esta visión, cada lectura sobre la línea delgada del panel superior muestra el poder adquisitivo, denominado en "útiles" universales, de los propietarios de las empresas más grandes de Estados Unidos que cotizan en bolsa ${ }^{4}$.

3 Gran parte de la economía es concebida, teorizada, medida y escrita en "términos reales", expresión que ponemos entre comillas porque nos parece muy problemática filosófica y empíricamente (ver Nitzan, 1989; Nitzan y Bichler, 2009a, cap. 8).

${ }^{4}$ El término "útil" fue ideado por Irving Fisher (1892)http://bnarchives.yorku. $\mathrm{ca} / 489 /$. Como esta unidad es ficticia e imposible de medir, los economistas convencionales pretenden que es teóricamente innecesaria. Pero en la práctica olvidan convenientemente esta pretensión y usan el "útil" en casi todo lo que hacen. La razón de esta hipocresía eclesiástica es simple: la única manera para que los economistas calculen agregados económicos reales (como el piв real y el volumen de capital real) o proporciones económicas reales (como las que comparan la paridad del poder adquisitivo o la productividad de distintos agentes económicos) es suponer una unidad de medida universal; y en el mundo hedonista de la economía, la única unidad de medida universal es el "útil" ficticio (Nitzan, 1992: cap. 5; Nitzan y Bichler, 2009a, caps. 5 y 8). 


\section{Gráfica 1}

Precios de las acciones en Estados Unidos, 1791-2016 (Dólares constantes)

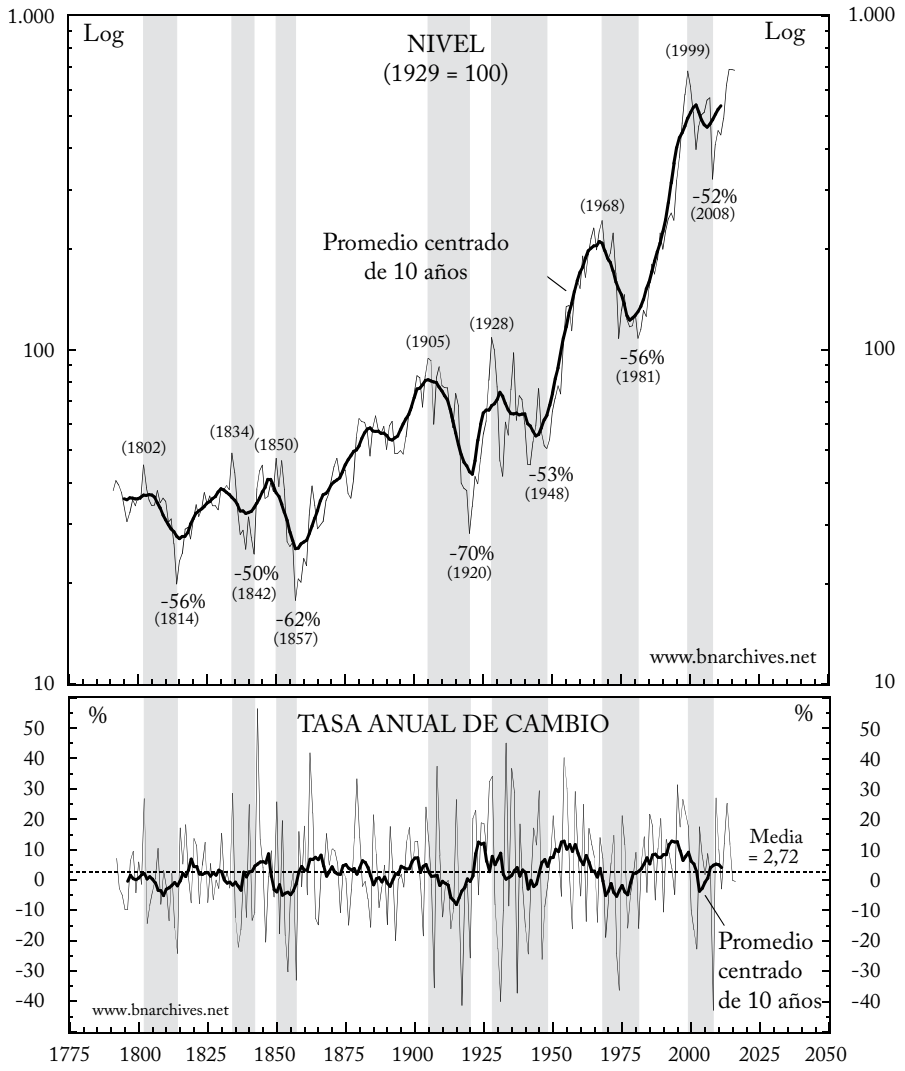

Nota: las áreas sombreadas indican los principales mercados bajistas (РМв) tal como se definen en el texto y en el cuadro 1. Las cifras negativas del panel superior indican el descenso del precio de mercado ajustado por el IPC desde el pico hasta el fondo del рмв (el año del fondo va entre paréntesis). El índice de precios de las acciones en Estados Unidos empalma las cuatro subseries siguientes: una combinación de series de acciones de bancos, seguros y ferrocarriles ponderada por GFD (1820-1870), el índice Cowles/Standard and Poor Composite (1871-1925), el índice 90-stock Composite (1926-1956) y el índice S\&P 500 (1957 hasta hoy). Las series en dólares constantes se calcularon dividiendo el índice del precio de las acciones por el IPC, con base 1929=100. El último punto de datos de la serie básica es 2016 y el del promedio centrado de diez años es 2011.

Fuentes: Precio de las acciones: Global Financial Data (GFD) hasta 1900 (código de serie: SPXD) y Standard and Poor's a través de Global Insight (GI) desde 1901 en adelante (código de serie: JS\&PNs). IPC: GFD hasta 1947 (código de serie: CPUSA) y FMI, Estadísticas Financieras Internacionales a través de GI desde 1948 en adelante (código de serie: L64@C111).

Por ejemplo, si la línea delgada sube un 10\%, eso significa que propietarios de acciones como Buffett y Soros pueden comprar un $10 \%$ más de alimentos (medido en útiles) o un 10\% más de combustible para 
sus vehículos (otra vez, medido en útiles). A la inversa, si esta línea baja el 30\% implica que los Buffett y los Soros del mundo pueden comprar un 30\% menos de ropa o gastar el 30\% menos en cuidado infantil (ambos medidos en útiles).

Por sorprendente que parezca, esta es la visión dominante. En un universo híper liberal, sigue el argumento, todo individuo, bien sea un propietario multimillonario o un pordiosero sin un céntimo $-\mathrm{y}$, por extensión, cada grupo de individuos, bien sea una corporación, un gobierno o una ONG- es impulsado en últimas por un deseo innato de maximizar el placer hedonista, y la conversión compulsiva de todas las medidas nominales en "términos reales" es una manera de guiar y medir esta obsesión utilitaria.

Pero hay otra manera, quizá más significativa, de pensar acerca de este cálculo. Cuando dividimos los precios de las acciones por el IPC, calculamos una relación entre los precios de dos canastas: una de acciones cotizadas en bolsa y una de bienes de consumo y servicios. Y si pensamos que los precios relativos de los bienes básicos reflejan el poder relativo de sus propietarios, lo que medimos no es solo el poder adquisitivo sino también el poder diferencial: el poder de quienes poseen acciones frente al poder de quienes poseen bienes de consumo y servicios. Por tanto, tenemos dos medidas en una: poder adquisitivo y poder diferencial; en lo que sigue nos centramos en este último.

\section{Hechos estilizados}

¿Qué nos muestra entonces la gráfica 1? Primero, que desde finales del siglo XVIII el poder diferencial de los propietarios de acciones respecto de los propietarios de bienes de consumo y servicios ha aumentado exponencialmente (cabe señalar que el panel superior usa una escala logarítmica; así, distancias verticales iguales representan múltiplos de 10). La tasa geométrica promedio de crecimiento de todo el periodo es del $1,28 \% 0^{5}$. Aunque esta cifra parezca pequeña, indica que en los últimos 215 años el poder relativo de los propietarios de acciones es casi 18 veces mayor. El panel inferior muestra la tasa anual de cambio. La línea delgada muestra el crecimiento de los precios de las acciones de Estados Unidos en dólares constantes de cada año con respecto al año anterior (la línea horizontal representa la tasa aritmética promedio de crecimiento del 2,72\%).

${ }^{5}$ La tasa geométrica de crecimiento se obtiene tomando la proporción entre la última y la primera observación, elevando esta proporción a la potencia $1 / n$ (donde $n$ es el número de años de la serie menos 1 ), sustrayendo 1 y multiplicando por 100. 
En cada panel hay también una línea gruesa, que representa el promedio centrado de diez años de la línea delgada respectiva. Cada observación de la línea gruesa es el valor promedio de la línea delgada respectiva (nivel o tasa de cambio) calculado para un intervalo de diez años. Como el promedio móvil es centrado, el intervalo corresponde a los cinco años anteriores a la observación y a los cinco años siguientes. Por ejemplo, el promedio centrado de diez años para 1990 es el valor promedio del periodo 1986-1995.

La línea gruesa del panel superior es útil para describir lo que llamamos "principales mercados bajistas" o $\mathrm{PMB}^{6}$. En un mercado cuyo precio sube exponencialmente, el acontecimiento más dramático es una baja prolongada о Рмв, al que definimos como un periodo en el que se cumplen dos condiciones: 1) declina el promedio centrado de diez años del precio de mercado en dólares constantes, y 2) cada pico de la línea anual es seguido por un pico más bajo (nótese que el pico/fondo de un рмв puede preceder/seguir ligeramente al punto de inflexión del promedio centrado de diez años). Con base en esta definición, contamos siete Рмв (sombreados): tres en la primera mitad del siglo XIX, tres en el xx y uno en el xxI. El panel superior señala los años pico y fondo de cada $\mathrm{PMB}$, junto con la caída total del precio de las acciones ajustado por el IPC. El cuadro 1 resume esta información.

Cuadro 1

Principales mercados bajistas de Estados Unidos

(Porcentaje, cálculos en dólares constantes)

\begin{tabular}{lc}
\hline Periodo (Pico-fondo) & Descenso \\
\hline $1802-1814$ & -56 \\
$1834-1842$ & -50 \\
$1850-1857$ & -62 \\
$1905-1920$ & -70 \\
$1928-1948$ & -53 \\
$1968-1981$ & -56 \\
$1999-2008$ & -52 \\
\hline
\end{tabular}

Nota: un рмв se define como un periodo multianual durante el cual: 1) el promedio centrado de diez años del precio de las acciones, en dólares constantes, tiende a bajar, y 2) cada sub pico sucesivo de la serie de precios subyacente es menor que el anterior. El pico/fondo de un PMB puede preceder/seguir ligeramente al punto de inflexión del promedio centrado de diez años.

\section{Cantidades y cualidades del poder}

Ahora bien, cuando el mercado está en auge, a los medios de comunicación populares les encanta insistir en que "esta vez es diferente". Las cabezas parlantes pretenden que algo fundamental cambió, y que los buenos tiempos pueden seguir para siempre. Irving Fisher hizo

${ }^{6}$ Para la génesis, versiones anteriores y análisis previos de este concepto, ver Bichler y Nitzan (2008), Kliman, Bichler y Nitzan (2011) y Bichler y Nitzan (2012a). 
esa afirmación infame en octubre de 1929 , poco antes de perder su fortuna, equivalente a 100 millones de dólares a precios de hoy, en el gran desplome de la Bolsa (New York Times, 1929), y de nuevo, en 1999, un par de analistas visionarios predijeron que el mercado de valores se triplicaría en cinco años, para verlo reducido a la mitad (Glassman y Hassett, 1999).

A los gurúes les gusta ridiculizar estos pronósticos de un "nuevo orden" con títulos como Exuberancia irracional (Shiller, 2000) y bromas como Esta vez es distinto (Reinhart y Rogoff, 2009). E1 mercado, dicen ellos, tiene un patrón natural, revertir a la media, y no hay nada que alguien pueda hacer para cambiarlo. A primera vista, parecen tener razón.

\section{Gráfica 2}

Tasa anual de cambio de los precios de las acciones en Estados Unidos (Promedio centrado de diez años)

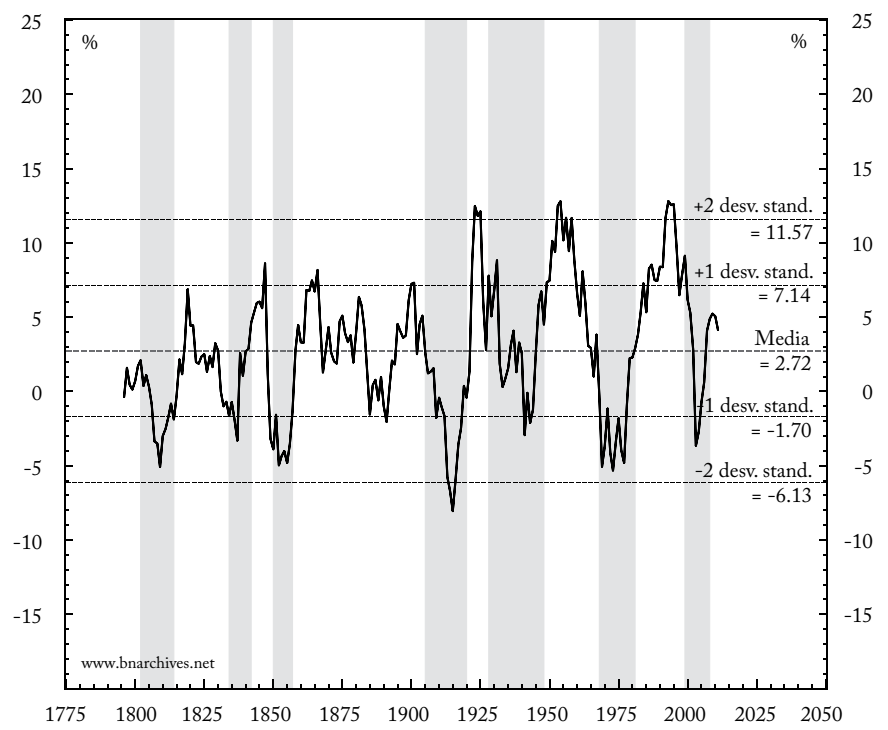

Nota: las áreas sombreadas indican los principales mercados bajistas (Рмв) tal como se definen en el texto y en el cuadro 1. El índice de precios de las acciones en Estados Unidos empalma las cuatro subseries siguientes: una combinación de series de acciones de bancos, seguros y ferrocarriles ponderada por GFD (1820-1870), el índice Cowles/Standard and Poor Composite (1871-1925), el índice 90-stock Composite (1926-1956) y el índice s\&P 500 (1957 hasta hoy). La serie en dólares constantes se calculó dividiendo el índice del precio de las acciones por el IPC, base 1929=100. El último punto de datos del promedio centrado de diez años es 2011.

Fuentes: Precio de las acciones: GFD hasta 1900 (código de serie: SPXD) y Standard and Poor's a través de GI desde 1901 en adelante (código de serie: JS\&PNS). IPC: GFD hasta 1947 (código de serie: CPUSA) y FMI, Estadísticas Financieras Internacionales a través de GI desde 1948 en adelante (código de serie: L64@C111). 
La gráfica 2 amplía el panel inferior de la gráfica 1, ignora las variaciones año a año y muestra únicamente el promedio centrado de diez años. Esta ampliación más limpia nos ayuda a distinguir tres patrones generales: 1) la tasa de crecimiento del precio de las acciones no es regular, pero revierte al promedio;2) no es aleatoria sino cíclica, y 3) su ciclo no es un azar, sino que en cambio muestra una duración más o menos estable (aunque su amplitud en el siglo xx es dos veces mayor que en el siglo xix). En general, el proceso se parece, entonces, a un fenómeno natural recurrente.

¿Pero lo es? Se puede observar que, durante el siglo pasado aproximadamente, cada Рмв fue seguido por un gran creordenamiento del poder capitalizado y una profunda reinterpretación del nomos capitalista ${ }^{7}$. Así, el de 1905-1920 fue seguido por el ascenso del capitalismo corporativo, el de 1928-1948 por el ascenso del Estado de bienestarguerra keynesiano y el de 1968-1981 por el ascenso del neoliberalismo global. A este respecto, el primer PM B del siglo XXI, de 1999 a 2008, parece incompleto: aunque el sistema capitalista ya está crujiendo, podría requerir otro PMB para llevar a un gran creordenamiento similar a los tres anteriores.

Lo más importante de estos creordenamientos es que son cualitativamente diferentes entre sí. Así, al final podemos decir que "esta vez -como las demás- es a la vez similar y diferente": cantidades similares de poder son guiadas por cualidades de poder diferentes.

\section{LA TESIS DEL DESAJUSTE}

¿Cómo dar sentido a estas pautas de largo plazo? Como ya se señaló, la teoría común y quizá la única en oferta es la tesis del desajuste. Según esta tesis, el capitalismo -como cualquier otro sistema económico-es un modo de producción y consumo que se puede describir y analizar en "términos reales" (es decir, en útiles). Cuando los economistas dicen que la economía creció el 5\%, lo que quieren decir -sean o no conscientes de ello- es que en este año se produjo un 5\% más de útiles que en el año anterior. Esta es la llamada esfera real de la economía.

Pero la economía capitalista tiene otra esfera, la financiera, y esta no se denomina en útiles reales sino en dólares y centavos nominales. El mercado de valores es parte de la esfera financiera y juega un papel

\footnotetext{
${ }^{7} \mathrm{E} 1$ verbo "creordenar" fusiona los aspectos dinámicos y estáticos de la creación de orden (Nitzan y Bichler 2009a, cap. 14). Los antiguos griegos usaban la palabra nomos para denotar las instituciones sociales-legales-históricas más amplias (Castoriadis, 1984; 1991). E1 nomos capitalista se explora en Nitzan y Bichler (2009a, cap. 9).
} 
crucial: actúa como un espejo gigante que refleja lo que sucede $-\mathrm{O}$, para ser más precisos, lo que ocurrirá- en la esfera real.

\section{Cámara de los espejos}

E1 diagrama 1 ilustra cómo funciona este espejo.

Diagrama 1

Cámara de los espejos de Fisher

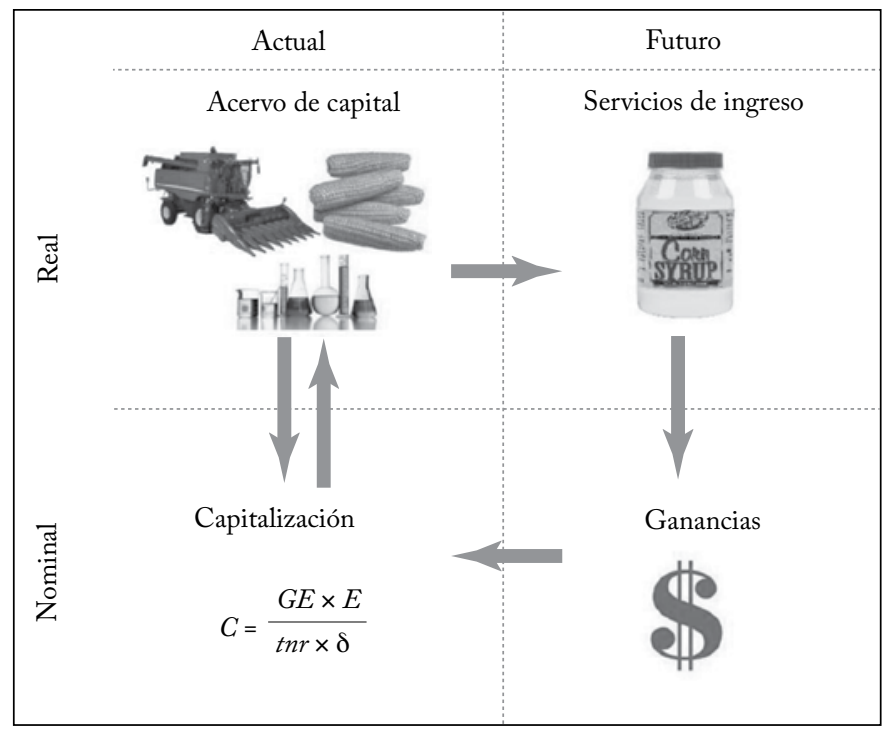

Según la tesis del desajuste, que se remonta a Irving Fisher (1896; 1907), los capitalistas poseen máquinas, materias primas y conocimiento, que en conjunto forman el "acervo de capital real" (cuadrante superior izquierdo). Este acervo de capital real producirá, en el futuro, servicios de ingreso real (cuadrante superior derecho) que los capitalistas a su vez venderán por ganancias nominales futuras (cuadrante inferior derecho). Y las expectativas de estas ganancias futuras son capitalizadas por sus propietarios, aquí y ahora, en el valor nominal de mercado actual (cuadrante inferior izquierdo) ${ }^{8}$. Ahora bien, si es-

8 Según Fisher, "La afirmación de que 'el capital produce ingreso' solo es verdadera en sentido físico; no es verdadera en el sentido del valor. Es decir, el capital-valor no produce ingreso-valor. En cambio, el valor-ingreso produce valorcapital [...] cuando el capital y el ingreso se miden en valor, su conexión causal es contraria a la que existe cuando se miden en cantidades. El huerto produce manzanas, pero el valor de las manzanas produce el valor del huerto [...] Vemos, entonces, que la riqueza de capital actual produce servicios de ingreso futuros, pero el valor-ingreso futuro produce valor-capital presente" (1907, 13-14, cursivas del 
tas transmutaciones son exactas, tenemos un ajuste; si son inexactas, tenemos un desajuste 9 .

\section{Capitalización, fundamentales y reversión a la media}

Limitemos nuestro ángulo de atención y examinemos la fase final de este proceso -es decir, del proceso de capitalización- usando la siguiente notación junto con las ecuaciones 1 a 3:

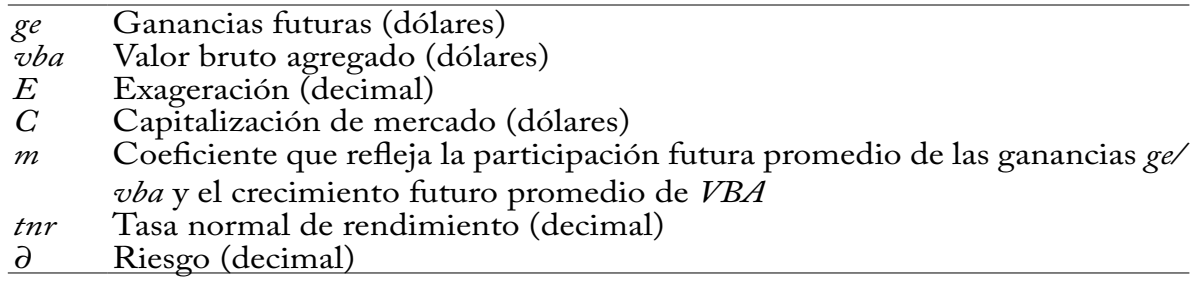

La ecuación 1 representa de qué manera los inversionistas capitalizan las ganancias futuras:

$C=(G E \times E) /(t n r \times \partial)$

E1 numerador representa la ganancia futura esperada y el denominador es la tasa de descuento. En el numerador, $G E$ es la ganancia futura real que se obtendrá. Como esta ganancia futura no se puede conocer aquí y ahora, los capitalistas deben conjeturarla; y usualmente sus proyecciones son demasiado optimistas o demasiado pesimistas. Este optimismo/pesimismo es captado por la $E$ del coeficiente de exageración. Cuando los capitalistas aciertan a dar en el blanco, $E=1$. Pero eso es excepcional. Normalmente, sus expectativas son muy altas, de modo que $E>1$, o muy bajas, de modo que $E<1$. El efecto neto de

original). Para una evaluación crítica del marco de Fisher, ver Nitzan y Bichler (2009a, 170-172).

9 Aunque en este artículo no profundizamos la idea siguiente, cabe señalar que la capitalización no se puede ajustar ni desajustar del "acervo de capital real”, por la más simple de las razones: este acervo no tiene -ni puede tener- una cantidad definida. Tal como es, el acervo de capital incluye varias entidades: máquinas, estructuras, materias primas y (dicen algunos) conocimiento; pero estas entidades no tienen una unidad común con la que se puedan agregar en una sola magnitud (recordemos que el útil universal es una ficción teórica y empírica, ver la nota 4). Esta imposibilidad fue señalada por Veblen y Wicksell a comienzos del siglo $\mathrm{xx}$, demostrada en las controversias de Cambridge sobre el capital en los años cincuenta y sesenta, y confirmada a regañadientes por las luminarias de la economía convencional poco después. Pero como aceptar esta conclusión habría corrido el piso a todo el edificio de la economía, los economistas siguen insistiendo en que el capital tiene una cantidad "real" y que su disciplina, así se base en una imposibilidad lógica-empírica, es una ciencia (para resúmenes críticos del marco de Fisher, ver Harcourt, 1969; 1972; Nitzan y Bichler, 2009a, caps. 5 y 8; Hunt y Lautzenheiser 2011, cap. 16). 
$E$ es aumentar o reducir la ganancia que los propietarios descuentan aqui y ahora en relación con la ganancia que ellos (o propietarios subsiguientes) realmente obtendrán en el futuro.

El denominador, que representa la tasa de descuento, tiene dos componentes. El primero es la tasa normal de rendimiento, tnr, que los capitalistas creen merecer por invertir en lo que llaman activos libres de riesgo (p. ej., bonos del gobierno que se mantienen hasta alcanzar su madurez). El segundo -el factor de escala $\partial-$ representa el rendimiento que los capitalistas exigen para compensar el riesgo relativo del activo en cuestión (en este caso, el riesgo de las acciones con respecto a los bonos del gobierno $)^{10}$. Por ejemplo, si la tasa normal de rendimiento es de 0,05 , el $5 \%$, y se estima que las acciones son dos veces más riesgosas que los bonos, $\partial$ será 2 y la tasa de descuento será de 0,1 , el 10\%.

El problema de la ecuación 1 es que las ganancias oscilan violentamente, de modo que para fines de predicción conviene tomar un atajo simplificador. En vez de estimar directamente la ganancia futura, los capitalistas y analistas suelen comenzar con el valor total de la producción en dólares, o valor bruto agregado, $v b a$, y luego hacen dos conjeturas. Mirando hacia el futuro profundo, proyectan que 1) $V B A$ crecerá a una tasa promedio del 5\%, por ejemplo; y 2) que la participación de la ganancia en vba oscilará alrededor de cierto promedio, por ejemplo, el $6 \%$. Uniendo estas dos conjeturas en un coeficiente $m$, pueden obtener la capitalización de mercado observando a $V B A y$ $m$ en vez de $E$; el coeficiente de exageración $E$ denota su optimismo/ pesimismo excesivo con respecto a la magnitud de $m$. Este nuevo cálculo se muestra en la ecuación 2 :

$C=(V B A \times m \times E) /(t n r \times \partial)$

La ecuación 3, que reordena los términos de la ecuación 2, muestra que la capitalización de mercado es el producto de dos componentes: 1) $V B A$, relativamente inequívoco, medido con regularidad y bastante aceptado; y 2) el producto/relación de los cuatro componentes restantes, que incluye una mezcla de conjeturas, convenciones difíciles de precisar y creencias cambiantes.

$C=V B A \times[(m \times E) /(t n r \times \partial)]$

Esta descomposición nos lleva al meollo de la tesis del desajuste. Si se conociera el futuro, el producto/relación de los cuatro elementos

${ }^{10} \mathrm{E} 1$ coeficiente de riesgo refleja la confianza relativa de los capitalistas en sus predicciones de ganancias; en este caso, la predicción de la ganancia empresarial en contraste con el pago de intereses sobre deuda del gobierno. 
del lado derecho de la ecuación 3 probablemente sería una constante: $m$ es prácticamente un número fijo (por definición), tnr sería un número fijo igual a la tendencia de crecimiento de $v b a$ y, como no hay incertidumbre, el coeficiente $E$ y el de riesgo serían iguales a 1.

Pero, como ya señalamos, el futuro no solo es desconocido sino incognoscible; y cuando los capitalistas y analistas tratan con lo ignoto, el resultado lamentable es, o así nos dicen, incertidumbre, irracionalidad y distorsiones. En suma, el segundo componente del lado derecho de la ecuación 3 seguramente oscilará. Pero esta oscilación, nos aseguran los defensores de la teoría, es parte integral de la tesis del desajuste: aunque la incertidumbre, la irracionalidad y las distorsiones abundan, no son ilimitadas. Aunque el movimiento del segundo elemento del lado derecho de la ecuación 3 sea de gran magnitud y larga duración, en últimas se autocorrige -o, en lenguaje estadístico más formal, revierte a la media-; y esta reversión a la media es la base teórica de todos los modelos de valoración de largo plazo.

\section{EL MODELO DE DESAJUSTE DE HUSSMAN}

Veamos ahora cómo se aplican estos principios en la práctica. En esta sección nos centramos en el modelo del administrador de fondos John Hussman, que, hasta donde sabemos, ofrece la mejor predicción de los rendimientos futuros de largo plazo ${ }^{11}$.

\section{El índice de desajuste de Hussman}

El modelo se basa en el índice de desajuste de Hussman (idh) dado por la ecuación 4:

IDH = capitalización de mercado/valor bruto agregado

Los dos componentes de $i d h$ se representan en la gráfica 3. La línea continua es la capitalización de mercado (el numerador de la ecuación 4) y la línea punteada es el valor bruto agregado (el denominador). Ambas corresponden a corporaciones no financieras con sede en Estados Unidos, se denominan en dólares y se representan en logaritmos ${ }^{12}$.

\footnotetext{
${ }^{11}$ El modelo de Hussman usa datos mensuales, mientras que nuestra reproducción emplea datos anuales. La justificación del modelo, los supuestos y las especificaciones técnicas se describen en Hussman (2015a; 2015b). Los artículos de Hussman se archivan en [http://www.hussmanfunds.com/weeklyMarketComment.html].

${ }^{12} \mathrm{La}$ decisión de Hussman de centrarse en las corporaciones financieras y no en todas las corporaciones no es teórica sino práctica: con el primer grupo se obtienen predicciones algo mejores que con el segundo.
} 
Gráfica 3

Corporaciones no financieras con sede en Estados Unidos (Miles de millones)

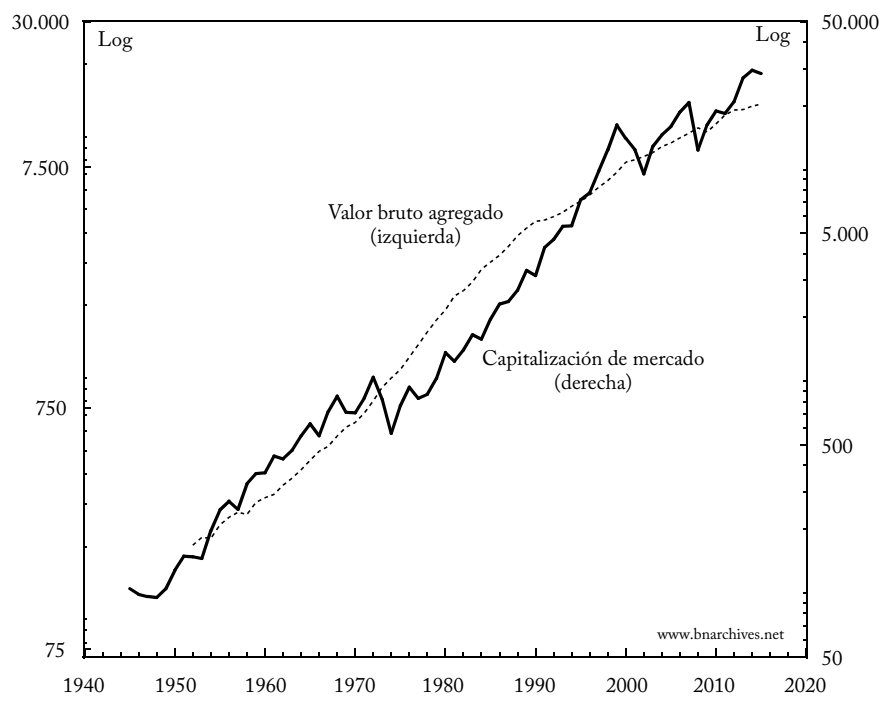

Nota: el valor de mercado de las corporaciones no financieras incluye activos que se mantienen en Estados Unidos y en el resto del mundo. Su valor bruto agregado es el valor bruto nacional agregado aumentado por el valor bruto agregado imputado de operaciones en el extranjero. Se calcula multiplicando el valor bruto nacional agregado de las empresas no financieras por $(1+$ ganancias de Estados Unidos por operaciones en el extranjero/ganancias después de impuestos en Estados Unidos); ambos componentes de las ganancias se suavizan usando promedios rezagados 5 años. El último punto de datos es 2015.

Fuente: Valor de mercado de las corporaciones no financieras: Federal Reserve Board Flow of Funds a través de GI (códigos de serie: LM103164103 para activos domésticos y LM263164103 para activos en el resto del mundo). Valor bruto nacional agregado de las corporaciones no financieras: Bureau of Economic Analysis (BEA) a través de GI (código de serie: GVANFC). Ganancias después de impuestos en Estados Unidos: BEA a través de GI (códigos de serie: ZAD para las ganancias domésticas después de impuestos, XFYADIV para los dividendos en el extranjero y XFYAREONUSDI para las ganancias en el extranjero reinvertidas).

La gráfica 4, que reproduce el diagrama básico de Hussman, representa el $i d h$ en el eje logarítmico izquierdo. La ecuación 5 muestra que este indicador es igual al componente de cuatro elementos del lado derecho de la ecuación 3. Y como sugiere la gráfica, el índice revierte de hecho a la media: fluctúa aproximadamente entre un bajo 0,6 y un alto 2,3 .

$I D H=C / V B A=m \times E / t n r \times \partial$ 


\section{Gráfica 4}

Índice de valoración de Hussman y rendimientos futuros

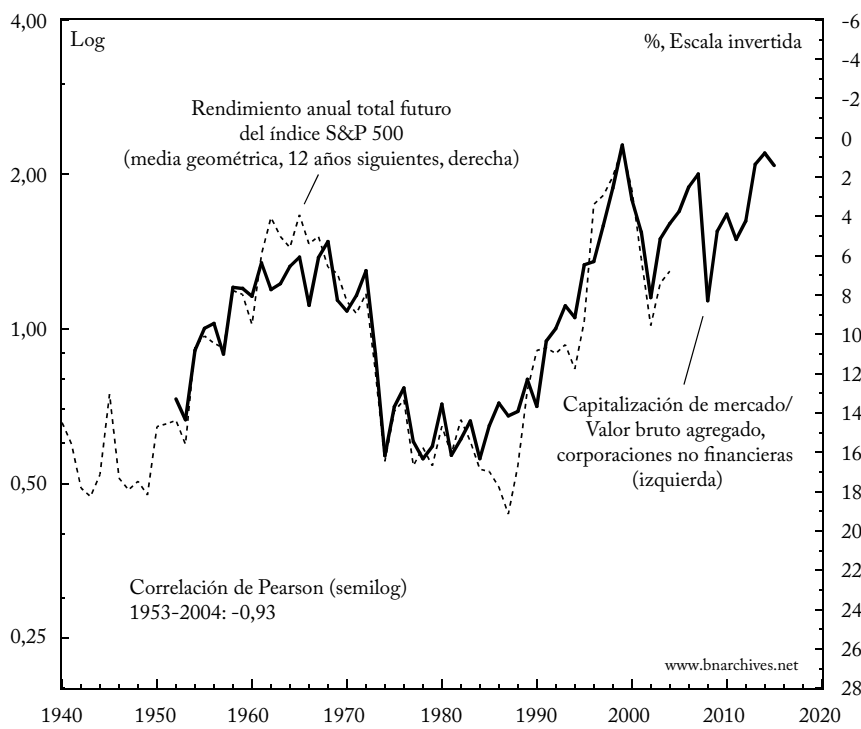

Nota: el valor de mercado de las corporaciones no financieras incluye activos que se mantienen en el país y en el resto del mundo. Su valor bruto agregado es el valor bruto nacional agregado aumentado por el valor bruto agregado imputado de operaciones en el extranjero. Se calcula multiplicando el valor bruto nacional agregado del sector empresarial no financiero por $(1+$ ganancias de Estados Unidos por operaciones en el extranjero/ganancias después de impuestos en Estados Unidos); ambos componentes de la ganancia se suavizan usando promedios rezagados 5 años. El rendimiento nominal anual total futuro del índice s\&P 500 se estima así: 1) se calcula la relación entre el índice de rendimiento total de los 12 años siguientes y su valor actual, y 2) se toma la raíz 12 de esa relación, se resta 1 y se multiplica por 100. La correlación semilogarítmica es entre el logaritmo del índice de valoración y el rendimiento futuro. Los últimos puntos de datos son 2015 para la relación valor de mercado/valor bruto agregado y 2004 para el rendimiento nominal anual total futuro.

Fuente: Rendimiento total nominal de S\&P 500: GFD hasta 1969 (código de serie:_SPXTRD) empalmado con datos de GI desde 1970 en adelante (código de serie: SP5OOTRI). Valor comercial de las corporaciones no financieras: Federal Reserve Board Flow of Fund a través de GI (códigos de serie: LM103164103 para activos domésticos y LM263164103 para activos en el resto del mundo). Valor bruto nacional agregado de las corporaciones no financieras: BEA a través de GI (código de serie: GVANFC). Ganancia después de impuestos en Estados Unidos: BEA a través de GI (códigos de serie: ZAD para las ganancias doméstica después de impuestos, XFYADIV para los dividendos en el extranjero y XFYAREONUSDI para las ganancias en el extranjero reinvertidas).

\section{Predicción de los rendimientos futuros}

Ahora bien, ¿por qué esta relación de desajuste es de interés para los inversionistas? Según Hussman, la razón está dada por la línea punteada de la gráfica 4, representada en el eje invertido derecho, que mide la tasa de rendimiento nominal anual total de las acciones en los futuros doce años. En otras palabras, cada observación indica las ganancias de capital y los dividendos que los inversionistas que 
compraron el índice s\&P 500 en ese año obtendrían en promedio durante los doce años siguientes.

Por ejemplo, un inversionista que compró el índice s\&P 500 en 1984 -cuando el $i d h$ era menor de 0,6- terminaría ganando un promedio anual del $16 \%$ durante los doce años siguientes. ¿Y cómo lo sabemos? Simplemente proyectamos la observación horizontalmente al eje derecho y leemos el resultado. $O$ tomemos un inversionista que compró en el pico de 1999, cuando el idh era cercano a 2,3. La proyección de la línea punteada sobre el eje derecho muestra que terminaría obteniendo un rendimiento nominal total promedio de menos del 1\% durante los doce años siguientes.

Lo que se debe señalar aquí es que los rendimientos totales futuros y el índice de desajuste de Hussman están correlacionados inversamente en forma casi perfecta: su coeficiente de correlación de Pearson es de $-0,93$, para un máximo de -1 . A primera vista, este resultado es notable: mientras que para los propietarios de acciones es difícil predecir lo que ocurrirá a sus inversiones en los próximos meses o en los dos años siguientes, según el modelo de desajuste de Hussman pueden saber muy bien lo que ganarán en los doce años siguientes. (A riesgo de poner la carreta delante del caballo, cabe observar que la lectura actual del $i d h$ es más o menos la misma que la de 1999, poco antes del inicio del último рмв. Lo que esta lectura implica se puede resumir en tres palabras siniestras: “llega el invierno".)

\section{Irracionalidad, riesgo y rendimientos}

Pero el registro predictivo casi perfecto del modelo es mancillado por dos observaciones inquietantes. La primera atañe a la "racionalidad económica". Los economistas convencionales insisten en que la acumulación prospera y fomenta la racionalidad (que para ellos significa que los precios monetarios reflejan utilidad, y que este reflejo implica óptimo de Pareto-asignación óptima de recursos-maximización de la utilidad). Pero la gráfica 4 parece sugerir exactamente lo contrario: cuanto más irracionales son los inversionistas, mayor es el desajuste aparente entre la capitalización nominal de mercado y los fundamentos reales; y cuanto mayor es el desajuste, mayor el margen de acumulación -bien sea comprando largo cuando el mercado está "sobrevendido" o corto cuando está "sobrecomprado" (con respecto a los fundamentos). En otras palabras, los inversionistas que maximizan la utilidad tienen interés en la "irracionalidad económica" y, por tanto, un incentivo para fomentarla. 
La segunda observación se refiere al riesgo y el rendimiento. Los textos de finanzas reiteran el mantra austriaco de que los dos van de la mano: como no puede haber ganancias sin dolor, o eso dicen, quienes desean ganar más deben estar dispuestos a asumir un riesgo mayor. Pero aquí también la gráfica 4 parece implicar lo contrario: conforme a los datos históricos, los mayores rendimientos futuros se presentan cuando el riesgo es más bajo (como a inicios de los años ochenta), mientras que cuando el riesgo es muy alto (p. ej., a finales de los noventa), los rendimientos eventuales son deprimentes. En otras palabras, los inversionistas son gorrones que consiguen algo por nada, o tontarrones que pagan algo por nada ${ }^{13}$.

\section{EL MODELO DE PODER}

Después de esbozar la cosmología convencional de las finanzas, pongámosla de cabeza esbozando nuestro modelo $\mathrm{CcP}_{\mathrm{c}}$ triangular. Seguimos tres pasos: primero examinamos el mercado de valores desde el punto de vista del poder capitalizado, luego relacionamos el poder capitalizado con el riesgo sistémico y después vinculamos el poder capitalizado y el riesgo sistémico con el sabotaje estratégico.

\section{El índice de poder}

La gráfica 5 presenta nuestro índice de poder y lo compara con el de Hussman. La línea punteada es el $i d h$ representado en el eje logarítmico derecho. La línea continua, en el eje logarítmico izquierdo, es el índice $i p$; definido como la relación entre el índice de precios S\&P 500 y la tasa media de salarios, normalizada considerando su promedio histórico $=100$ :

IP = Índice del precio de las acciones/Tasa de salarios

¿Por qué la relación entre el índice de precios s\&P 500 y la tasa de salarios es un "índice de poder"? Para contestar esta pregunta, recordemos que el $i d h$ intenta ajustar la capitalización de mercado (que representa el poder adquisitivo agregado de los poseedores de acciones) con los fundamentos subyacentes de esta capitalización (una proxy de los servicios de ingreso agregados que producirá el acervo de capital real correspondiente).

${ }^{13}$ La posición de Hussman sobre este asunto no es del todo clara. Por un lado, alerta a sus lectores de que las acciones muy sobrevaloradas constituyen una combinación tóxica de máximo riesgo y rendimiento mínimo (ver, p. ej., Hussman $2000 ; 2016$ ). Por otra parte, hasta donde podemos decir, guarda silencio acerca de por qué debería existir este perfil riesgo/rendimiento teóricamente embarazoso. 


\section{Gráfica 5 \\ Valoración de las acciones de Estados Unidos: ¿desajuste o poder?}

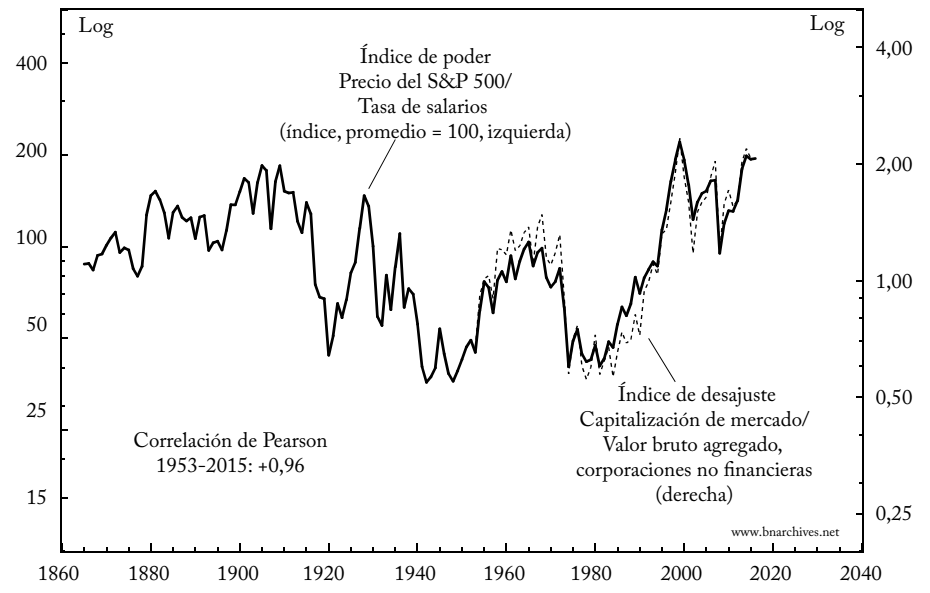

Nota: el valor de mercado de las corporaciones no financieras incluye activos que se mantienen en el país y en el resto del mundo. Su valor bruto agregado es el valor bruto nacional agregado aumentado por el valor bruto agregado imputado de operaciones en el extranjero. Se calcula multiplicando el valor bruto nacional agregado del sector empresarial no financiero por $(1+$ ganancias de Estados Unidos por operaciones en el extranjero/ganancias después de impuestos en Estados Unidos); ambos componentes de la ganancia se suavizan usando promedios rezagados 5 años. El precio de s\&P 500 empalma las cuatro subseries siguientes: una combinación de series de acciones de bancos, seguros y ferrocarriles ponderada por GFD (1820-1870), el índice Cowles/Standard and Poor Composite (1871-1925), el índice 90-stock Composite (1926-1956) y el índice s\&p 500 (desde 1957 hasta hoy). La tasa de salarios empalma la tasa de salarios por hora de los trabajadores en la producción manufacturera hasta 1946 con la tasa de salarios por hora de los trabajadores del sector no agrícola desde 1947 en adelante. Los últimos puntos de datos son 2015 para el índice de desajuste y 2016 para el índice de poder.

Fuente: Valor de mercado de las corporaciones no financieras: Federal Reserve Board Flow of Funds través de Gi (códigos de serie: LM103164103 para activos domésticos y LM263164103 para activos en el resto del mundo). Valor bruto nacional agregado de las corporaciones no financieras: BEA a través de GI (código de serie: GVANFC). Ganancia después de impuestos en Estados Unidos: BEA a través de GI (códigos de serie: ZAD para las ganancias doméstica después de impuestos, XFYADIV para los dividendos en el extranjero y XFYAREONUSDI para las ganancias en el extranjero reinvertidas). Precio S\&P 500: GFD hasta 1900 (código de serie: _SPXD) y GI desde 1901 en adelante (código de serie: JS\&PNS). La tasa de salarios por hora empalma las siguientes series: Historical Statistics of the United States, Millennial Edition Online: salarios por hora en manufacturas, todos los oficios, 1865-1889 (código de serie: Ba4290), salario por hora en la manufactura, todas las industrias, 1890-1913 (código de serie: Ba4299), salario semanal de los trabajadores en la producción de manufacturas, 1914-1918 (código de serie: Ba4362), salario por hora de los trabajadores en la producción de manufacturas, 1919-1938 (código de serie: Ba4361); GI: salarios promedio por hora de los trabajadores en la producción de manufacturas, 1939-1946 (código de serie: AHPMFNs); Conference Board a través de GI: remuneración promedio por hora de todos los empleados del sector no agrícola (código de serie: JRWSSNFE).

\section{Nuestro índice ip es muy diferente. Primero, traslada la discusión del simbolismo ontológico al simbolismo operativo ${ }^{14}$. Cabe señalar que, a}

${ }^{14}$ La noción del "capital como poder" en cuanto símbolo operativo fue sugerida y elaborada por Ulf Martin (2010). Siguiendo a Sybille Kramer, Martin distingue tres tipos de símbolos: mágico (la entidad es el símbolo), ontológico 
diferencia de Hussman, no comparamos el poder adquisitivo general y los servicios de ingreso, solo comparamos precios. Para Hussman, la capitalización nominal de mercado es un símbolo ontológico: representa, exacta o inexactamente, una entidad externa; en este caso los útiles "reales" que generará el acervo de capital "real". En contraste, consideramos los precios de las acciones y la tasa de salarios como símbolos generativos u operacionales. Su relación no representa una realidad externa, constituye esa realidad; en este caso el poder capitalizado de los propietarios impuesto a la población.

La segunda diferencia es que los componentes de ip -precio de las acciones y tasa de salarios- son criaturas totalmente diferentes. A diferencia del numerador y del denominador del modelo de desajuste de Hussman, no hay ninguna razón para que se ajusten y, por tanto, ninguna razón para que se desajusten.

Esto no es casualidad. Mientras que el universo liberal intenta armonizar sus categorías, el cosmos del $\mathrm{CcP}$ las enfrenta mutuamente. De hecho, en vez de reflejarse uno a otro, el numerador $y$ el denominador del ip representan un conflicto, el choque entre quienes poseen los medios capitalizados de poder y quienes son controlados por ellos. Cabe observar que aquí usamos la tasa media de salarios no como una medida de productividad o de bienestar, sino como referencia para medir el poder diferencial de los propietarios. Además, aunque en sentido estricto la tasa de salarios pertenece únicamente a los trabajadores empleados, su movimiento temporal es una proxy, por tosca que sea, de las condiciones cambiantes de la población subyacente en general. Por tanto, cuando ip aumenta, esto no significa que el mercado esté distorsionado ni que los inversionistas sean económicamente irracionales, sino que aumenta el poder de los propietarios de acciones con respecto al de la población; y viceversa cuando ip disminuye. Además, y muy importante, este poder relativo es prospectivo: no solo denota la posición relativa de los gobernantes aquí y ahora, sino también cómo esperan que cambie en el futuro.

En suma, los índices de desajuste y de poder son conceptualmente distintos y teóricamente no relacionados. No obstante $-\mathrm{y}$ aquí llega-

(el símbolo representa una entidad mundana distinta) y operativo (el símbolo define la entidad). De acuerdo con Martin, el capital como poder se entiende mejor como un símbolo operativo debido a que define su propia lógica, y crea y recrea la realidad social. Esta propiedad "generativa/operativa" es destacada por Cochrane (2016) quien relaciona la familia china con la capitalización diferencial del índice s\&P/Tsx, y por Malik y Phillip (2012) y Malik (2014) que utilizan el mercado de arte y de derivados para demostrar el carácter no ontológico de la capitalización. 
mos a la parte importante-, a pesar de esas diferencias fundamentales se correlacionan en forma casi perfecta: según la gráfica 5 , su coeficiente de Pearson, durante más de medio siglo, es de $+0,96$, para un máximo de +1 .

\section{¿Desajuste o poder?}

¿Qué explica esta correlación notablemente estrecha? ¿Es una casualidad estadística milagrosa o hay una conexión oculta entre estos indicadores aparentemente diferentes? La respuesta surge de las ecuaciones 7 a 11, que relacionan el índice de desajuste de Hussman con nuestro índice de poder. La ecuación 7 descompone la capitalización de mercado $C$ y el valor bruto agregado $V B A$ en sus componentes respectivos de precio y cantidad (el precio promedio de las acciones $p$ y el número de acciones en circulación $n$ para la primera, el deflactor del valor bruto agregado $D V B A$ y el valor bruto agregado real para el segundo).

\begin{tabular}{ll}
\hline$v b a$ & Valor bruto agregado (dólares) \\
$d v b a$ & Deflactor del valor bruto agregado (dólares) \\
$C$ & Capitalización de mercado (dólares) \\
$N$ & Número de acciones en circulación \\
$P$ & Índice de precios del mercado de valores (dólares) \\
Relación de precios & $w / d v b a$ (decimal) \\
$Q$ & Valor bruto agregado "real” (decimal) \\
Relación de cantidades & $n / q$ (decimal) \\
Residuo & $n / q \times$ x drba (decimal) \\
$W$ & Tasa de salarios (dólares) \\
\hline
\end{tabular}

$I D H=C / V B A=(P \times N) / D V B A \times Q$

La ecuación 8 divide y multiplica el denominador del $i d h$ por la tasa de salarios $w$ y reacomoda los términos:

$I D H=(P \times N) /[(D V B A / W) \times W \times Q]=P / W \times N / Q \times W / D V B A$

Las ecuaciones 9 a 11 hacen reordenamientos adicionales para acentuar la conexión entre los índices de desajuste y de poder:

$I D H=I P \times N / Q \times W / D V B A$

$I D H=I P \times$ Relación de cantidades $\mathrm{x}$ Relación de precios

$I D H=I P \times$ Residuo

La ecuación 11 muestra que el índice de poder ip-es decir, el conflicto capitalizado entre propietarios de acciones y la población subyacentees de hecho parte integral del índice de desajuste de Hussman, IDH, mientras que la correlación casi perfecta de la gráfica 5 sugiere que 
ip es el principal impulsor de $I D H$. El impacto combinado de $I D H$ y de las relaciones de cantidad y precio es un residuo insignificante ${ }^{15}$.

En este sentido, la teoría del desajuste nos recuerda la visión geocéntrica de Ptolomeo. La idea de que los epiciclos solares alrededor de la tierra daban lugar a predicciones bastante precisas, aunque no obstante era errónea ${ }^{16}$. Y quizá lo mismo se pueda decir de la noción de que los capitalistas y analistas fijan el precio del mercado de valores para ajustarlo a los fundamentos reales de utilidad y productividad: así como la visión geocéntrica, esta noción da lugar a predicciones bastante exactas, e igual que la visión geocéntrica parece totalmente errónea. La verdadera fuerza motriz no es aquí el desajuste de la utilidad futura sino los cambios en el poder organizado.

\section{Poder capitalizado y rendimientos futuros}

Además, conforme a la gráfica 6, parece que esta realidad actual del poder capitalizado -y no la realidad desajustada de la utilidad y la productividad- es la que rige los rendimientos futuros. La gráfica muestra dos líneas. La línea continua es nuestro índice de poder, representada en el eje logarítmico izquierdo. La línea punteada, en el eje invertido derecho, es el rendimiento nominal anual total del índice S\&P 500, proyectado doce años adelante. Por conveniencia, la gráfica muestra el promedio histórico del índice de poder $(=100)$, una desviación estándar por debajo y dos desviaciones estándar por arriba y los últimos cuatro рмв (sombreados).

En la parte inferior izquierda se presentan los coeficientes de correlación de Pearson de varios periodos. En general, la correlación entre poder capitalizado y rendimientos futuros es más débil antes de 1929 que después. Pero el periodo relevante para la comparación es 1953-2004, los años que cubre el modelo de Hussman en la gráfica 4. Para este periodo, la correlación es de 0,85 , solo un poco menor que la de Hussman, de -0,93 (lo que es de esperar, dada la contribución adicional del factor Residuo).

\footnotetext{
${ }^{15}$ Históricamente, la Relación de cantidades ha tendido a bajar y la Relación de precios a subir. Además, los dos movimientos se han compensado relativamente, de modo que su producto -el Residuo de la ecuación 11- ha terminado desplazándose lateralmente, mostrando poca o ninguna correlación con los índices de desajuste y de poder.

${ }^{16}$ Para una comparación sucinta entre el antiguo modelo geocéntrico y el modelo heliocéntrico, ver Singh (2004, en particular el cuadro 2, 34-35).
} 


\section{Gráfica 6}

El índice de poder y los rendimientos futuros

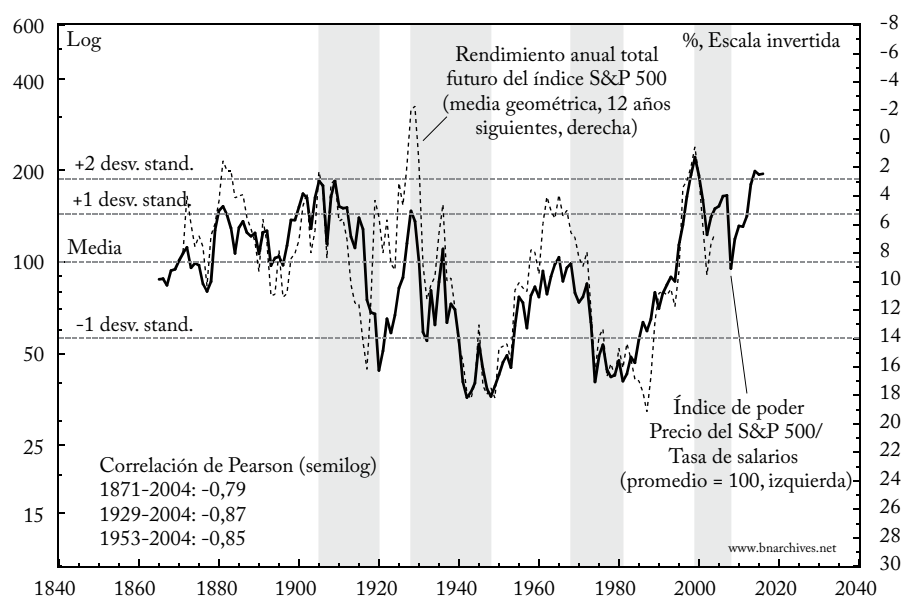

Nota: los años sombreados indican los Рмв tal como se definen en el cuadro 1 . Las series se normalizaron haciendo su promedio histórico $=100$. El precio $\mathrm{s} \& \mathrm{P} 500$ empalma las cuatro subseries siguientes: una combinación de series de acciones de bancos, seguros y ferrocarriles ponderada por GFD (1820-1870), el índice Cowles/Standard and Poor Composite (1871-1925), el índice 90-stock Composite (1926-1956) y el índice S\&P 500 (desde 1957 hasta hoy). La tasa de salarios empalma salarios por hora de trabajadores en la producción manufacturera hasta 1946 con salarios por hora de trabajadores del sector no agrícola desde 1947 en adelante. E1 rendimiento nominal anual total futuro del índice S\&P 500 se estima así: 1) se calcula la relación entre el índice de rendimiento total de los 12 años siguientes y su valor actual, y 2) se toma la raíz 12 de esa relación, se resta 1 y se multiplica por 100. La correlación semilogarítmica es entre el logaritmo del índice de valoración y el rendimiento futuro. Los últimos puntos de datos son 2015 para la relación valor de mercado/valor bruto agregado y 2004 para el rendimiento nominal anual total futuro.

Fuente: Precio del s\&P 500: GFD hasta 1900 (código de serie: SPXD) y gi desde 1901 en adelante (códigos de serie: Js\&PNS). La tasa de salarios por hora empalma las siguientes series: Historical Statistics of the United States, Millennial Edition Online: salarios por hora en manufacturas, todos los oficios, 1865-1889 (código de serie: Ba4290), salario por hora en la manufactura, todas las industrias, 1890-1913 (código de serie: Ba4299), salario semanal de los trabajadores en la producción de manufacturas, 1914-1918 (código de serie: Ba4362), salario por hora de los trabajadores en la producción de manufacturas, 1919-1938 (código de serie: Ba4361); GI: salarios promedio por hora de los trabajadores en la producción de manufacturas, 1939-1946 (código de serie: AHPMFNs); Conference Board a través de GI: remuneración promedio por hora de todos los empleados del sector no agrícola (código de serie: JRWSSNFE). Rendimiento total nominal de S\&P 500: GFD hasta 1969 (código de serie:_SPXTRD) empalmado con datos de GI desde 1970 en adelante (código de serie: SP500TRI).

\section{Irracionalidad, riesgo y rendimientos (reconsiderados)}

\section{De modo que la diferencia entre los índices de desajuste y de poder no es empírica sino teórica, y aquí debemos volver a los dos puntos que planteamos al final de la sección anterior: la cuestión de la irra- cionalidad y la relación entre riesgo y rendimiento.}


Comencemos con la irracionalidad. Si los capitalistas y analistas fueran perfectamente racionales y totalmente clarividentes, el elemento de cuatro componentes del lado derecho de la ecuación 3 sería un número fijo, la capitalización de mercado fluctuaría en paralelo con el valor bruto agregado e $i d h$ trazaría una línea recta horizontal igual al promedio histórico del índice. Así debería ser en un mundo perfectamente ajustado.

Pero eso no es lo que vemos en la práctica. Si observamos el índice de poder de la gráfica 6 -que, como vimos en la gráfica 5, es casi una copia al carbón del $i d h-$ vemos que menos del $15 \%$ de las observaciones son iguales al promedio normalizado del índice. Las demás son mayores o menores. En otras palabras, desde el punto de vista de la tesis del desajuste, el mercado es, en términos generales, económicamente irracional. Además -y aquí llegamos al punto clave- a la irracionalidad casi siempre se la culpa de diversas formas de poder, desde información asimétrica y errores de política hasta imperfecciones del mercado e intervenciones extraeconómicas. Pero, entonces, si la valoración es casi siempre inexacta y sus desviaciones son en su mayoría asuntos de poder, ¿por qué no dejar a un lado la irracionalidad y las distorsiones y centrarse directamente en lo que todos parecen estar más de acuerdo, es decir, en el poder? Una vez la atención se centra en el poder, nada que ajustar y, por tanto, ningún desajuste. Y una vez desaparece el desajuste, no hay nada irracional en que el índice de valoración suba y baje. Sus movimientos solo reflejan el cambiante paisaje del poder.

La segunda diferencia atañe al riesgo y el rendimiento. Como ya señalamos, los manuales de finanzas estipulan que el riesgo y el rendimiento deben tener una correlación positiva; aunque, según los modelos de desajuste y de poder, su correlación sea de hecho negativa. Ahora bien, así esta correlación negativa no concuerde con los fundamentos de la tesis del desajuste, es consistente con los fundamentos de nuestro modelo CcP. Igual que el índice de desajuste, el poder capitalizado predice que los rendimientos futuros guardan una relación negativa: cuanto mayor el poder, menor el rendimiento. Por dos razones: 1) el poder siempre se ejerce mediante algún tipo de sabotaje estratégico (un concepto al que volvemos más adelante), y el sabotaje suscita resistencia; 2) cuanto mayores son el poder y el sabotaje, mayor la resistencia que provocan. Si todo lo demás es igual, para los capitalistas es más fácil aumentar su poder cuando IP está una o dos desviaciones estándar por debajo de su promedio (como en los años cuarenta y ochenta, p. ej.) que cuando está una o dos des- 
viaciones estándar por encima (como en los noventa y hoy en día). Esta intensidad cambiante de la resistencia $-\mathrm{y}$ el hecho de que vaya de la mano con el poder- es la que hace que nuestro índice de poder revierta, y esta reversión a la media es la que determina que el riesgo y el rendimiento tengan una relación negativa, no positiva.

A este respecto, parece que dos desviaciones estándar por encima del promedio constituyen la asíntota histórica, o el límite, del poder capitalizado de las acciones en Estados Unidos ${ }^{17}$. Esta asíntota se alcanzó tres veces en los 150 años anteriores -a comienzos del siglo pasado, a finales de los noventa y hoy en día- y las dos primeras veces se produjo una reversión significativa en forma de un рмв. En otras palabras, cuando el poder capitalizado se acerca a sus asíntotas, los capitalistas tienen buenas razones para temer su propio poder. Así llegamos al segundo aspecto de nuestro modelo: el temor sistémico.

\section{TEMOR SISTÉMICO}

Hace siete años, en medio de la crisis financiera, escribimos un artículo en el que argumentamos que los capitalistas padecían temor sistémico: que no estaban preocupados por las crecientes tasas de interés ni por la caída de las ganancias, sino por la existencia misma del sistema que conocían ${ }^{18}$. También argumentamos que su temor sistémico se podía identificar empíricamente, considerando el co-movimiento de los precios de las acciones y las ganancias corporativas (Nitzan y Bichler, 2009b; ampliado en Bichler y Nitzan, 2010).

\section{Identificación del temor sistémico}

Nuestra lógica se puede resumir como sigue. La capitalización es prospectiva: según el gurú de la valoración Benjamin Graham, no se deben descontar las ganancias corrientes sino las ganancias que se obtendrán en el futuro, en el camino a la "eternidad" (citado en Zweig, 2009, 28). En este esquema, las variaciones actuales de las ganancias solo tienen un impacto insignificante en el resultado final. Y, de hecho, si se revista la ecuación 3, se verá que la capitalización

${ }^{17}$ Para diferentes análisis de las asíntotas de poder, ver Bichler y Nitzan (2012a), Kliman, Bichler y Nitzan (2011) y Bichler y Nitzan (2014).

18 "Esta conciencia [la del capitalista atado al volante de una megamáquina enloquecida] se ha sentido angustiada no por esto o por aquello [la caída de las ganancias o el aumento de la volatilidad], no por este o por aquel momento [una fuerte corrección del mercado o una declaración de guerra], sino por su esencia entera; pues ha sentido el miedo de la muerte, el señor absoluto [la ira de los gobernados]. Ese temor la disolvió interiormente, la hizo temblar en lo más íntimo y estremeció todo lo fijo que había en ella [¿ंsobrevivirá el capitalismo?]" (Hegel, 1807, 237; parafraseado en Bichler y Nitzan, 2010, 19). 
depende del coeficiente $m$, que a su vez depende de la participación promedio de las ganancias futuras en vba y de la tasa media de crecimiento futura de $v b a$. Las ganancias corrientes ni siquiera figuran en la ecuación.

Esta confianza ritual en el futuro implica confianza sistémica. Muestra la creencia en que las ganancias seguirán fluyendo y que los activos siempre tendrán compradores; en otras palabras, que el sistema es eterno y el símbolo operativo de la capitalización dominará el mundo para siempre.

Imaginemos ahora la situación contraria -un ambiente en el que los capitalistas pierden esa confianza sistémica en el futuro y son agobiados por el temor sistémico. ¿Qué ocurre cuando empiezan a dudar. ¿Qué ocurre cuando el índice de poder está en su máximo histórico y se preocupan porque la actual arquitectura del poder es insostenible; cuando los principales promotores de la globalización tiran la toalla, diciendo que la globalización no funciona; cuando algunos Estados periféricos salen de la órbita de la superpotencia y otros se desintegran por completo; cuando las predicciones económicas convencionales fracasan miserablemente y las autoridades nacionales parecen ignorarlo; cuando la desigualdad llega a extremos históricos y la población arde de descontento; cuando el ecosistema se desestabiliza y la extracción de recursos enfrenta el agotamiento?

El resultado de estos desarrollos es el temor sistémico, la aprensión de que el modo actual de poder pueda derrumbarse.

Aunque la reacción inmediata de los gobernantes al temor sistémico no es la capitulación sino la negación: “¿Qué?, ¿nosotros los capitalistas nos preocupamos? ¿Temor por nuestro sistema? ¡En absoluto!”. Pero, entonces, para respaldar esta negación y mantener la apariencia de confianza, necesitan probar que aún están al mando, y la prueba que tienen más a mano de ese control son las ganancias actuales. $\mathrm{Si}$ siguen siendo altas -0 , mejor aún, si siguen aumentando- entonces nosotros, los capitalistas, podemos mantener la esperanza pese al futuro amenazador. $\mathrm{Y}$ si nuestro grupo en su conjunto mantiene la esperanza, entonces, como inversionistas individuales, todos nosotros tenemos buenas razones para mantener e incluso aumentar nuestros portafolios de acciones.

Es paradójico que la prueba del temor sistémico sea su misma negación. Podemos saber que los capitalistas han sido golpeados por el temor sistémico por el hecho de que nieguen y abandonen su ritual central de la capitalización prospectiva; y podemos saber el grado en que niegan este ritual por la medida en que su fijación del precio 
de los activos pasa a depender de las ganancias actuales y no de las ganancias futuras.

En un trabajo anterior usamos esta prueba empírica por negación para argumentar que hubo dos periodos durante los cuales los capitalistas fueron golpeados por el temor sistémico: los años treinta y los de la primera década de este siglo (Nitzan y Bichler, 2009b; 2010). Demostramos nuestro argumento en tres pasos: primero graficamos las tasas anuales del cambio de precios de las acciones y de las ganancias corrientes por acción (GPA) suavizadas por promedios rezagados tres años; luego comparamos visualmente los co-movimientos de esas tasas de cambio; y, por último, identificamos las dos décadas mencionadas como los dos únicos periodos en que ambas series parecían estrechamente correlacionadas ${ }^{19}$. Infortunadamente nuestro método no fue muy riguroso, y esa falta de rigor nos llevó a cometer un grave error empírico: no pudimos identificar dos periodos adicionales en los que las series mostraban una correlación positiva, y esta falla suscitó un acalorado debate en el Journal of Critical Globalization Studies (Kliman, Bichler y Nitzan, 2011).

\section{El índice de temor sistémico}

Por ello, aquí intentamos hacer las cosas de modo diferente. Primero, no consideramos las tasas de cambio de los precios de las acciones y de las GPA, como hicimos antes, sino sus niveles. Las medidas de correlación ya reflejan el cambio, de modo que correlacionar tasas de cambio es similar a considerar la segunda derivada en vez de la primera. Segundo, acortamos el intervalo de comparación entre el precio y las GPA actuales. Quizá el intervalo original de tres años era demasiado amplio para capitalistas miopes; por ello aquí lo reducimos a doce meses. Por último, en vez de ojear el intervalo de correlación entre las tasas de cambio de los precios de las acciones y de las GPA, lo medimos sistemáticamente a medida que se desplaza sobre todo el conjunto de datos ${ }^{20}$.

E1 resultado de estas modificaciones se muestra en la gráfica 7. El panel superior muestra los precios mensuales normalizados y las GPA del grupo de compañías s\&P 500, desde 1871. El panel inferior muestra las correlaciones de corto plazo. La línea delgada es la co-

${ }^{19}$ En sentido estricto, el término "ganancias 'corrientes' por acción" es inapropiado: en la práctica, los datos de GPA se reportan como ganancias promedio por acción registradas en los doce meses anteriores. En este sentido, todos los datos de ganancias corrientes son de hecho retrospectivos.

${ }^{20}$ Ulf Martin sugirió y demostró empíricamente que aquí se debía usar una correlación móvil (comunicación privada con los autores, mayo de 2014). 
rrelación rezagada 12 meses entre series de precios y GPA del panel superior. Cada observación muestra la correlación durante el último año, con un valor que oscila entre -1 (correlación inversa perfecta) y +1 (co-movimiento directo perfecto).

\section{Gráfica 7}

Precio del índice s\&P 500 y GPA: el índice de temor sistémico

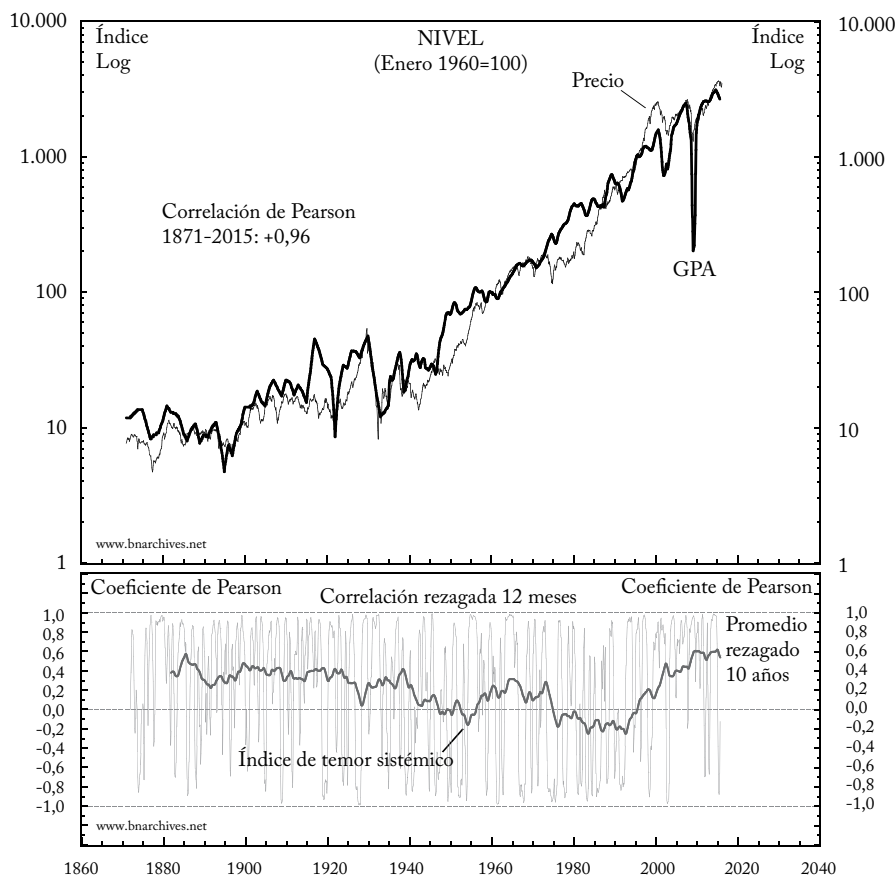

Nota: el índice S\&P 500 empalma las cuatro subseries siguientes: una combinación de series de acciones de bancos, seguros y ferrocarriles ponderada por Global Financial Data (1820-1870), el índice Cowles/Standard and Poor Composite (1871-1925), el índice 90-stock Composite (1926-1956) y el índice s\&P 500 (desde 1957 hasta hoy). La correlación rezagada 12 meses del panel inferior (línea delgada) mide la correlación entre precio y GPA (ganancias por acción). El promedio rezagado diez años (línea gruesa) es la media de esta correlación rezagada en los últimos 120 meses. Los últimos puntos de datos son septiembre de 2015 para las GPA y abril de 2016 para el precio.

Fuente: Precio y GPA de S\&P 500: archivos de datos en línea de Robert J. Shiller [http://www. econ.yale.edu/ shiller data.xls], acceso del 20 de abril de 2016.

La dificultad de la correlación rezagada 12 meses es que oscila ampliamente; por ello la mera inspección no es aquí muy reveladora. La línea gruesa del panel inferior resuelve esta dificultad suavizando la línea delgada mediante el promedio rezagado diez años. Cada observación sobre la línea gruesa mide la correlación promedio rezagada 12 
meses entre el precio y la GPA de los últimos años diez. A esta serie la llamamos indice de temor sistémico ${ }^{21}$.

\section{Evolución histórica del temor sistémico}

La gráfica 8 amplía nuestro índice de temor sistémico tomado del panel inferior de la gráfica 7 , para que sea más fácil de examinar.

\section{Gráfica 8}

El índice de temor sistémico

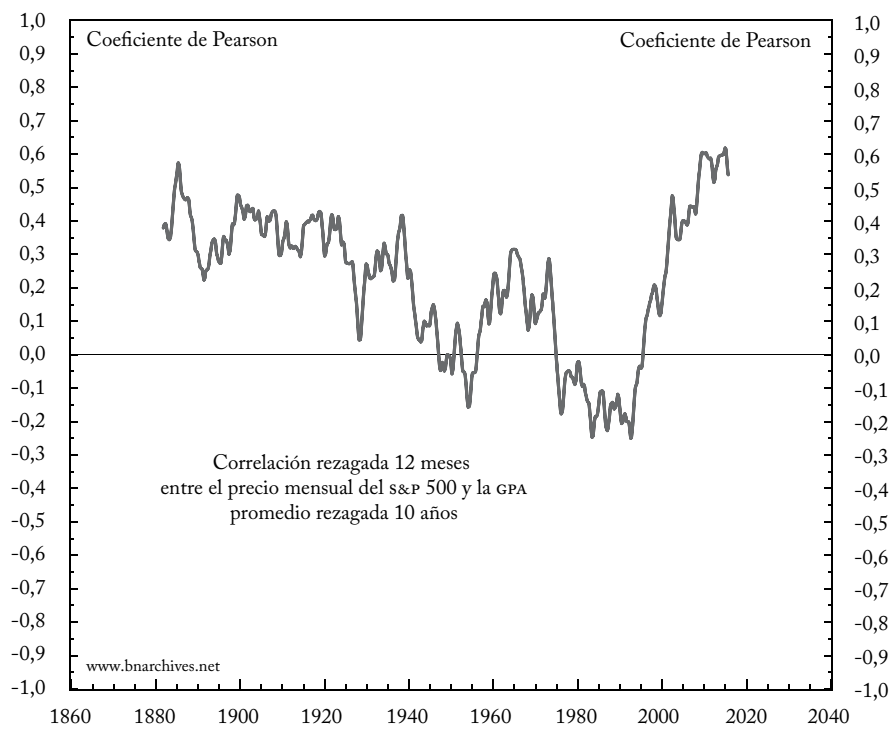

Nota: el índice de temor sistémico se calcula en dos etapas: 1) se calcula la correlación rezagada 12 meses entre el precio y la GPA del índice s\&P 500; 2) se calcula el promedio móvil de diez años de la correlación rezagada 12 meses calculada en el primer paso. El índice s\&P 500 empalma las cuatro subseries siguientes: una combinación de series de acciones de bancos, seguros y ferrocarriles ponderada por GFD (1820-1870), el índice Cowles/Standard and Poor Composite (1871-1925), el índice 90-stock Composite (1926-1956) y el índice s\&P 500 (desde 1957 hasta hoy). El último punto de datos es septiembre de 2015.

Fuente: Precio y GPA de S\&P 500: archivos de datos en línea de Robert J. Shiller [http://www. econ.yale.edu/ shiller data.xls], acceso del 20 de abril de 2016.

La gráfica muestra dos patrones claros: uno a largo plazo y otro a corto plazo. El patrón de largo plazo tiene forma de V, con el punto bajo a comienzos de la década de 1990. Hasta comienzos de la década de 1920, cuando la capitalización prospectiva estaba aún en su infancia, la correlación entre el precio y la GPA era muy alta, cerca de

${ }^{21}$ Por ejemplo, el índice de temor sistémico para septiembre de 2015 (la última observación de la serie) es de $+0,538$. Este resultado se obtiene promediando las 120 lecturas mensuales de las correlaciones rezagadas 12 meses entre agosto de 2005 y septiembre de 2015. 
$+0,4$. Pero, aun así, ya había una baja visible, y a comienzos de los años cuarenta se había convertido en un fuerte declive. Los métodos de descuento se estaban introduciendo entonces en los manuales, y en los cincuenta, cuando el ritual de la capitalización fue cada vez más aceptado e internalizado por los inversionistas en acciones, la correlación cayó casi a 0 , y desde entonces siguió oscilando alrededor de ese valor, aunque con algunas oscilaciones significativas. La reversión decisiva se produjo a comienzos de los noventa. Inicialmente, el alza parecía ser parte de otra oscilación breve. Pero a comienzos de este siglo se hizo evidente (al menos en retrospectiva) que se había roto la tendencia a la baja que duró un siglo. En vez de revertir a 0 , el índice de temor sistémico siguió aumentando y, a comienzos de la última década, llegó al máximo histórico de +0,6.

Sin embargo, este patrón en forma de $\mathrm{V}$ ha sido todo menos suave. Oscilando alrededor de las tendencias hacia abajo y hacia arriba vemos muchas fluctuaciones de corto plazo, algunas de ellas muy pronunciadas. Por tanto, la pregunta que debemos abordar es qué está detrás de estos patrones: ¿qué determina la forma de $\mathrm{V}$ de largo plazo del índice y qué explica sus fluctuaciones de más corto plazo?

\section{¿Cultura o poder?}

A nuestro leal saber y entender, nunca se ha hecho esta pregunta, y mucho menos se ha respondido. De hecho, hasta donde sabemos, el patrón en forma de $\mathrm{V}$ de la correlación precio-GPA de corto plazo, que se muestra en las gráficas 7 y 8 , es un nuevo hallazgo.

Es usual oír que, desde los años ochenta, el capitalismo estadounidense se ha caracterizado por el énfasis creciente en "el valor para los accionistas", el aumento del "cortoplacismo" y la obsesión casi universal por el aumento trimestral de las ganancias. Esta opinión popular concuerda con el alza de la correlación precio-GPA de los años ochenta que muestra la gráfica 8; y esta consistencia no nos debería sorprender. Cuando los capitalistas prestan cada vez más y más atención al último resultado y los analistas están pegados a la última noticia, no es extraño que los mercados bursátiles sean cada vez más sensibles a las variaciones más recientes de las ganancias ${ }^{22}$.

¿Pero cuál es la causa de estos cambios? ¿Por qué se ha acortado el horizonte de tiempo capitalista? ¿Por qué los inversionistas, que durante todo un siglo hasta esos años se preocupaban cada vez menos por las ganancias corrientes y parecían ser muy felices por comprar y

${ }^{22}$ Esta idea fue planteada por Suhail Malik en la presentación de este trabajo en la Conferencia CcP de 2016 [http://bnarchives.yorku.ca/489/]. 
mantener acciones a largo plazo, de pronto empezaron a insistir en el aumento trimestral de las ganancias? ¿La reversión de la forma de $\mathrm{V}$ de comienzos de los noventa es solo la consecuencia de una "cultura de la inversión” cambiante? ¿Es solo una nueva moda pasajera marcada por los vientos teóricos del neoliberalismo justo a tiempo y alentada por la flama ideológica de Margaret Thatcher, Ronald Reagan y Alan Greenspan, o estos desarrollos son el resultado de un cambio más profundo?

La evidencia que presentamos más adelante sugiere esto último. Argumentamos que los capitalistas y los analistas de hoy en día llegaron a exigir aumentos trimestrales de las ganancias no porque "les gustara", porque fueran seducidos por una nueva "moda" financiera o estuvieran convencidos de que los incrementos de corto plazo son "económicamente más eficientes" que el crecimiento de largo plazo. En nuestra opinión, los exigen porque se ven obligados, y la fuerza que los obliga nada tiene que ver con las razones anteriores. La razón es, más bien, que su poder capitalizado se está acercando a sus asíntotas, y para ellos la única manera de contrarrestar su gran temor sistémico es presionar por mayores ganancias corrientes.

\section{El co-movimiento del poder capitalizado y del temor sistémico}

La gráfica 9 muestra la relación de largo plazo entre temor sistémico y poder capitalizado. La gráfica incluye dos series. La línea punteada, representada en el eje derecho, es nuestro índice de temor sistémico, tomado de la gráfica 8. Para reiterar, este índice es el promedio rezagado diez años de la correlación rezagada 12 meses entre el precio de S\&P 500 y la GPA. La línea continua, en el eje logarítmico izquierdo, es nuestro índice de poder, tomado de la gráfica 6 y suavizado como un promedio rezagado diez años para que corresponda a la periodicidad del índice de temor sistémico.

La correlación entre ambas series es muy estrecha: su coeficiente de Pearson para los últimos 132 años es de +0.83 , para un máximo de +1 . Esta correlación nos dice que cuanto mayor es el poder capitalizado de los propietarios de acciones con respecto a la población subyacente, mayor es su temor sistémico y, por tanto, mayor su confianza en las ganancias corrientes al fijar el precio de sus acciones; y, a la inversa, cuanto menor su poder capitalizado, menor su temor sistémico y, por tanto, menor su énfasis en la ganancia actual. 


\section{Gráfica 9}

La dialéctica del poder y el temor

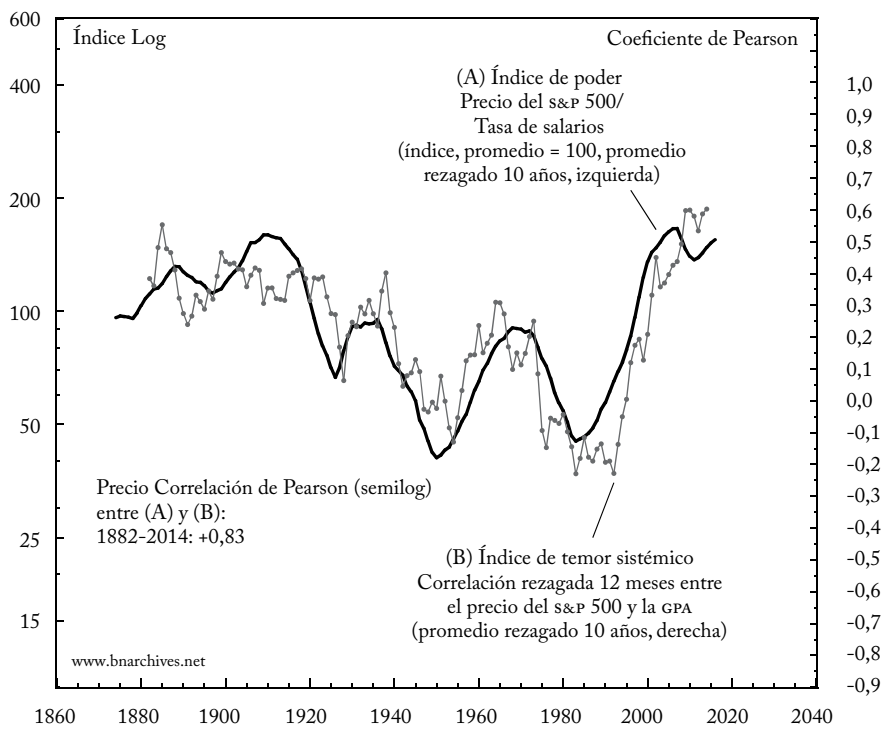

Nota: el índice de temor sistémico representa los promedios anuales de la serie mensual de la gráfica 7 (ver allí su definición). El precio del índice s\&P 500 empalma las cuatro subseries siguientes: una combinación de series de acciones de bancos, seguros y ferrocarriles ponderada por GFD (1820-1870), el índice Cowles/Standard and Poor Composite (1871-1925), el índice 90-stock Composite (1926-1956) y el índice s\&P 500 (desde 1957 hasta hoy). La tasa de salarios empalma salarios por hora de trabajadores en la producción manufacturera hasta 1946 con salarios por hora de trabajadores del sector no agrícola desde 1947 en adelante. Los últimos puntos de datos son 2014 para el índice de temor sistémico y 2016 para el índice de poder.

Fuente: Precio anual del s\&P 500: GFD hasta 1900 (código de serie: SPXD) y GI desde 1901 en adelante (códigos de serie: JS\&PNs). La tasa de salarios por hora empalma las siguientes series: Historical Statistics of the United States, Millennial Edition Online: salarios por hora en manufacturas, todos los oficios, 1865-1889 (código de serie: Ba4290), salario por hora en la manufactura, todas las industrias, 1890-1913 (código de serie: Ba4299), salario semanal de los trabajadores en la producción de manufacturas, 1914-1918 (código de serie: Ba4362), salario por hora de los trabajadores en la producción de manufacturas, 1919-1938 (código de serie: Ba4361); Gi: salarios promedio por hora de los trabajadores en la producción de manufacturas, 1939-1946 (código de serie: AHPMFNs); Conference Board a través de GI: remuneración promedio por hora de todos los empleados del sector no agrícola (código de serie: JRWSSNFE). Precio y GPA mensuales de s\&P 500: archivos de datos en línea de Robert J. Shiller [http://www.econ.yale. edu/ shiller/data.xls], acceso del 20 de abril de 2016.

\section{La dialéctica del poder y el temor}

A primera vista, este co-movimiento puede parecer contraintuitivo. ¿Por qué los capitalistas temen más por su sistema cuando se hacen más poderosos? ¿No debería ser al contrario, es decir, cuanto mayor su poder, menor su temor sistémico? 
Para contestar esta pregunta debemos retroceder un poco. E1 poder es un concepto complejo y a menudo elusivo. Tiene muchas dimensiones y capas, es históricamente contingente y dependiente del contexto y, sobre todo, dialéctico y auto transformador. En nuestra investigación extendemos la noción científica de fuerza de Johannes Kepler para considerar el poder capitalizado no como una entidad cualitativa independiente sino como una relación cuantitativa entre entidades (Nitzan y Bichler, 2014,141). En este artículo definimos este poder en forma muy amplia, como la relación entre propietarios de acciones y población subyacente, medida por la relación entre precios de las acciones y tasa de salarios. Pero también argumentamos que la cantidad de poder capitalizado expresa la confianza de los gobernantes en la obediencia de los gobernados (Nitzan y Bichler 2009a, 17); en este caso, la confianza de los propietarios de acciones en la obediencia de la población.

Pero la confianza en la obediencia no es un sentimiento monolítico. Si quisiéramos generalizar, podríamos decir que la acumulación de poder provoca no uno sino dos movimientos, uno extrovertido y el otro introvertido, y que sus trayectorias no son similares sino opuestas. En el exterior, la relación parece ser positiva: cuanto mayor es el poder de los gobernantes, mayor es su demostración de confianza en la obediencia. Pero en el interior, la conexión es negativa: cuanto más poderosos son, mayor es el temor de que su poder se derrumbe.

Esta relación de doble faz es el eje del Leviatán de Hobbes (2002). Las capacidades relativamente iguales de los seres humanos, dice él, suscitan incertidumbre, inseguridad y sospecha mutua, y estas fuerzas a su vez los obligan a tratar de aumentar sin cesar su poder diferencial. Pero, entonces -y este es el cualificador esencial- cuanto más poder se posee, más se teme perderlo. El resultado es un ciclo continuo en el que el temor alimenta el hambre de poder, y la acumulación de poder agrava el temor que alimenta esa hambre (ver, p. ej., Hobbes, 2002, 75 y 94).

Consideremos ahora cómo se desarrolla este doble movimiento en nuestro caso. Planteamos que los capitalistas se ven impulsados a aumentar sin cesar su poder capitalizado, y que ese aumento fomenta su confianza manifiesta en la obediencia. ¿Y cómo sabemos que esta confianza está aumentando? Porque los precios de las acciones incluidos en el numerador de IP son determinados por los capitalistas, y estos los determinan arriesgando lo que más aprecian: su propio dinero. De hecho, la única razón para que los capitalistas compren acciones y así aumenten la relación precio de las acciones/salarios es 
que esperan que esta relación aumente aún más. Y el hecho de que crean que esta relación aumentará testimonia su confianza en la obediencia - la confianza en que la población no los expropiará y que el sistema en su conjunto no les fallará. En este sentido, nuestro índice de poder ofrece una medida objetiva de la confianza capitalista, al menos en el exterior.

Pero como muestra la gráfica 9, hay otro proceso en acción, un proceso interior: la base temporal de la confianza capitalista en la obediencia varía con el nivel de poder capitalizado. Cuando el índice de poder es bajo, la confianza proyectada de los capitalistas es intrínsecamente prospectiva. Durante esos periodos - p. ej., los años cuarenta u ochenta- los capitalistas se centran en el futuro e ignoran del todo la ganancia corriente (como indica la correlación precio-GPA baja, nula o incluso negativa). ¿Por qué? Debido a que, cuanto menor es el poder capitalizado, mayor es el margen para aumentarlo: cuanto más se pueda redistribuir el ingreso en favor de las ganancias, más se puede ampliar la exageración, más se puede reducir la volatilidad de las ganancias y más se puede bajar la tasa normal de rendimientos. $\mathrm{Y}$ siempre y cuando estos elementos se puedan aumentar/reducir en favor del capital, los propietarios pueden ignorar con seguridad el presente sombrío y centrarse en el futuro prometedor.

Pero cuando el índice de poder es alto -como lo fue, p. ej., a comienzos del siglo xx y como lo es ahora- la confianza en la obediencia se debe basar principalmente en el presente (y así lo hace, como indica la alta correlación precio-GPA en esos periodos). ¿Por qué? Debido a que el poder capitalizado no es ilimitado. Cuanto mayor es el poder, mayor es la resistencia al poder. Y cuando el poder se acerca a sus asíntotas -en este caso, cuando la participación de las ganancias en el ingreso y el nivel de exageración ya son altos y la volatilidad del ingreso y la tasa normal de rendimientos ya son bajas- aumentarlo aún más dentro de los límites existentes de la "máquina simbólica", como la llama Ulf Martin (2010), es cada vez más difícil ${ }^{23}$. Tales aumentos exigen amenazas, sabotaje y fuerza abierta adicionales, los que a su vez llevan a que el sistema sea cada vez más complejo y frágil, y por tanto propenso a la depresión (Bichler y Nitzan, 2010). En esas circunstancias, la única manera de que los capitalistas mantengan su confianza aparente es que estén continuamente seguros de que el sistema aún funciona, aquí y ahora. $\mathrm{Y}$ como el futuro es demasiado sombrío para confiar en él, esta seguridad solo puede provenir de las ganancias actuales.

${ }^{23}$ Bichler y Nitzan (2012a) examinan algunos de estos límites en Estados Unidos. 


\section{El augur}

Los gobernantes siempre necesitan un augur, una bola de cristal que refuerce su confianza y fortalezca su resolución. Pero a veces el augur se niega a cooperar, y cuando desobedece la fachada se desmorona y los gobernantes se encuentran frente al vacío. La literatura of rece muchos ejemplos ilustres: la reina malvada en Blancanieves de los hermanos Grimm, cuyo obediente espejo mágico de repente la desafía y le dice que no es la más bella; Gengis Kan en Un día más largo que un siglo de Aitmatov (1983), cuya nube leal que lo guía desaparece de pronto y deja hecha jirones la conquista del kan trotamundos; Belsasar, el omnipotente rey de Babilonia, cuya soberbia se desinfla cuando aparece una escritura misteriosa en la pared (Libro de Daniel, cap. 5); y la lista continúa.

Pero estos espejos de poder son muy ingenuos. Solo reflejan una imagen binaria, y sus advertencias casi siempre llegan demasiado tarde. En cambio, la correlación precio de las acciones-GPA produce reflejos infinitamente matizados. En vez de una imagen binaria, dibuja una escala continua, de un coeficiente de Pearson de 0 (o menos)-lo que indica que los capitalistas prospectivos no temen por su sistema- $\mathrm{a}+1$, lo que significa que los capitalistas, agobiados por el temor sistémico, han abandonado su creencia central en la capitalización prospectiva en favor de una postura defensiva, retrospectiva.

La gráfica 10 muestra históricamente este rango analítico. La gráfica presenta la misma serie de datos de la gráfica 9, pero no los representa en una escala de tiempo sino uno contra otro. Cada observación anual proyecta dos lecturas: el promedio rezagado diez años del índice de poder en el eje horizontal y el índice de temor sistémico en el eje vertical. Las observaciones se agrupan fuertemente en torno a una pendiente positiva, y constatan lo que ya vimos en la gráfica 9: que el poder capitalizado está ligado estrechamente al temor sistémico. Para fines ilustrativos, dibujamos una línea discontinua para señalar la evolución de esta relación temporal en el periodo más reciente: de 1983, cuando el índice de temor sistémico estaba en el mínimo, a 2014, cuando alcanzó el máximo.

E1 "estiramiento" gradual de esta línea discontinua se asemeja a jalar una cuerda: a medida que Estados Unidos se movía hacia arriba y a la derecha de esta trayectoria, la tensión entre sabotaje y resistencia aumentaba y aumentaba. Pero debido a que el proceso ha sido tan lento y prolongado, este amento fue casi imperceptible. De hecho, hasta poco los mismos "actores" clave -capitalistas y administradores de fondos, junto con los encargados de política y los formadores de 
opinión- no eran conscientes de ello y rara vez lo admitían, ni siquiera para sí mismos (y menos aún de la manera que aquí se describe). Pero como Veblen podría haber dicho, aunque no lo reconozcan con su mente ya lo saben en su corazón. Y aquí sus acciones hablan más fuerte que sus palabras: con su poder en aumento, han abandonado gradual pero sistemáticamente su ritual sagrado de capitalización prospectiva en favor del presente aún color de rosa. Su actual modo de poder es cada vez más inestable, y los precios de sus acciones de corto plazo indican que tras la soberbia se oculta la profunda aprensión de que no perdure.

Gráfica 10

La dialéctica del poder y el temor, 1882-2014

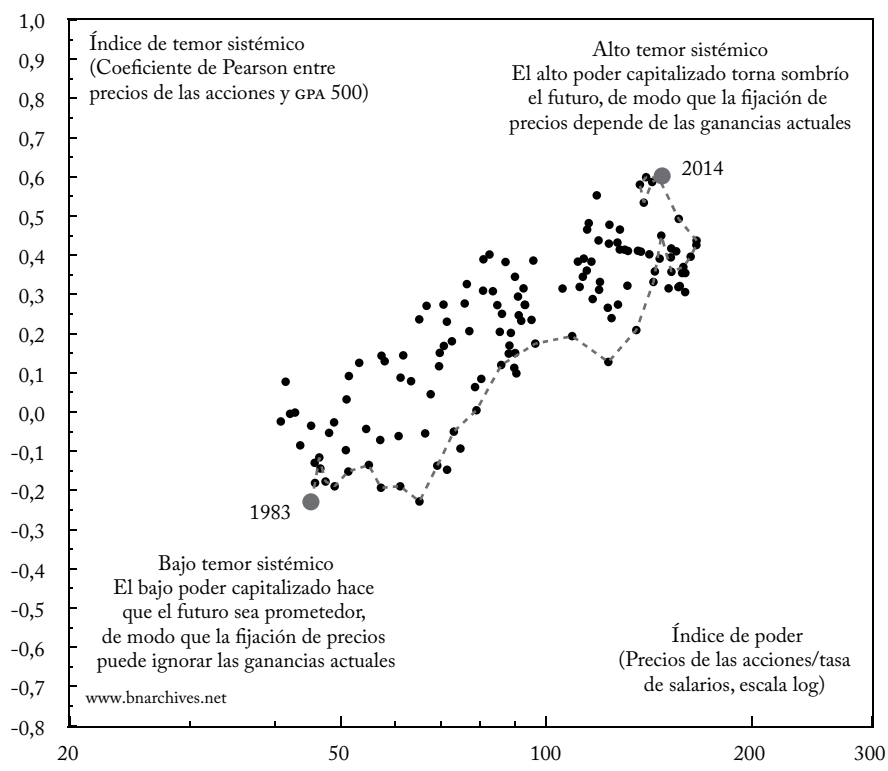

Nota y fuentes: ver la gráfica 9.

Nuestro estudio de la redistribución como eje clave del poder capitalista empezó a comienzos de los años ochenta. En ese momento, el poder capitalizado y el temor sistémico en Estados Unidos estaban en su mínimo histórico, los inversionistas eran totalmente inconscientes del asunto y nuestro trabajo se calificó de "economía social" (con un regusto de "justicia social" moralizante). Pero a medida que el poder capitalizado y el temor sistémico aumentaron, la importancia esencial de la redistribución subió lentamente a la superficie y, en 2014, cuando el poder y el temor alcanzaron máximos históricos, el trabajo 
de Thomas Piketty (2014) sobre la desigualdad de pronto fue noticia de primera plana y todos supieron que el $1 \%$ superior mantenía al resto del mundo bajo su poder.

Entonces el discurso empezó a cambiar. Aunque las cabezas parlantes aún aclaman al capitalismo como el mejor de todos los mundos posibles, empezamos a ver cada vez más expresiones de culpa (el FMI admite que el proyecto neoliberal de globalización fue "sobrevendido"; Ostry, Loungani y Furceri, 2016), de remordimiento (McKinsey \& Co. dice que la actual generación es más pobre que sus padres; McKinsey \& Co. et al., 2016); y advertencias terribles (el ex rey de los bonos Bill Gross alerta a sus socios: aunque "soy un inversionista que definitivamente cree en el sistema", creo que "el sistema está en riesgo"; Gittelsohn, 2016). Con la tensión en su máximo histórico, muchos inversionistas sensatos sospechan que tarde o temprano el resorte se romperá, y cuando la confianza se derrumbe y los gobernantes se agolpen a las puertas de la bolsa de valores, se iniciará un nuevo Рмв.

\section{La base temporal de la confianza en la obediencia}

En suma, los índices de poder y de temor sistémico nos dicen dos cosas opuestas sobre la perspectiva capitalista: el índice de poder expresa la confianza externa de los capitalistas en la obediencia y el índice de temor sistémico indica su aprensión interna de que el modo de poder no perdure. Aunque apuntan en distinta dirección, las dos medidas están íntimamente entrelazadas: el índice de temor sistémico muestra la base temporal de la confianza capitalista. Cuando el poder es bajo, la confianza se basa en el futuro y en la capitalización prospectiva. Pero a medida que el poder aumenta, su base se traslada al presente; y este cambio, que implica una confianza creciente en la ganancia actual, manifiesta la ruptura progresiva de la capitalización prospectiva y el temor cada vez mayor por el futuro del sistema.

\section{SABOTAJE ESTRATÉGICO}

Esta discusión nos lleva al tercer aspecto de nuestro modelo CcP triangular: la afirmación de que el poder capitalizado y el temor sistémico son impulsados por el sabotaje estratégico ${ }^{24}$.

\footnotetext{
${ }^{24} \mathrm{E} 1$ concepto de sabotaje estratégico - la idea de que los gobernantes dominan la sociedad socavando, limitando y reorientando estratégicamente la autonomía, la creatividad y la productividad de la comunidad para sus propios fines- fue expuesto por Thorstein Veblen $(1904 ; 1923)$. Este concepto es central para nuestro trabajo sobre el modo capitalista de poder (Nitzan y Bichler, 2009a, cap. 12), y ha sido examinado, investigado y extendido en numerosas publicaciones CcP. Para un resumen de obras sobre el tema, ver Bichler y Nitzan (2015b).
} 


\section{¿E1 mercado de valores es procíclico o contracíclico?}

Es innecesario decir que esta afirmación es diametralmente opuesta a la tesis del desajuste. La opinión dominante es que los mercados financieros oscilan alrededor de sus fundamentos económicos y que la oscilación es procíclica. Cuanto más sólidos son los fundamentos, mayor es el optimismo y, por tanto, mayor la "sobrerreacción"; y, a la inversa, cuanto más débiles son los fundamentos, más profundo es el pesimismo y, por tanto, mayor la "subreacción". Por esta razón se supone que las "burbujas" del mercado se inflan cuando la economía está en auge y se desinflan cuando se estanca.

Ahora bien, en nuestros trabajos hemos mostrado que la mayoría de las veces el mercado de valores no es procíclico. Como demuestran las gráficas 9 y 10, los precios de las acciones oscilan junto con las ganancias actuales solo cuando el mercado es muy "costoso" (es decir, cuando el poder capitalizado es muy alto). Cuando las valoraciones son moderadamente altas, promedio, bajas o muy bajas -lo que sucede la mayoría de las veces- los movimientos del precio y de las ganancias actuales son bastante inconexos. Además, como demostramos en análisis anteriores de la tesis del desajuste, las tasas de crecimiento a largo plazo del "capital financiero" (bonos y acciones) y del "capital real" (medido en dólares corrientes) no se correlacionan positiva sino negativamente (Bichler y Nitzan, 2009; 2015a). Lo que quisiéramos argumentar aquí es que este movimiento contrario del mercado de valores y de la llamada economía subyacente refleja las bases del $s a-$ botaje de la acumulación.

\section{Crecimiento del empleo}

Empecemos con la gráfica 11, que muestra dos series. La primera es nuestro índice de poder, suavizado como promedio rezagado diez años y representado en el eje logarítmico izquierdo. La segunda es la tasa anual de crecimiento del empleo, también suavizada como promedio móvil de diez años, representada en el eje derecho. Nótese que la serie de crecimiento del empleo está rezagada cinco años. Este rezago significa que, si hay una conexión, estas series se pueden considerar como un indicador anticipado o predictor del índice de poder.

La razón para centrarnos en el crecimiento del empleo es que es una buena proxy de las perspectivas del desajuste y del poder. Desde el punto de vista del desajuste, el crecimiento del empleo es una medida directa de la actividad económica (a diferencia del crecimiento del PIB, que es resultado de esa actividad). Desde la perspectiva del poder, el 


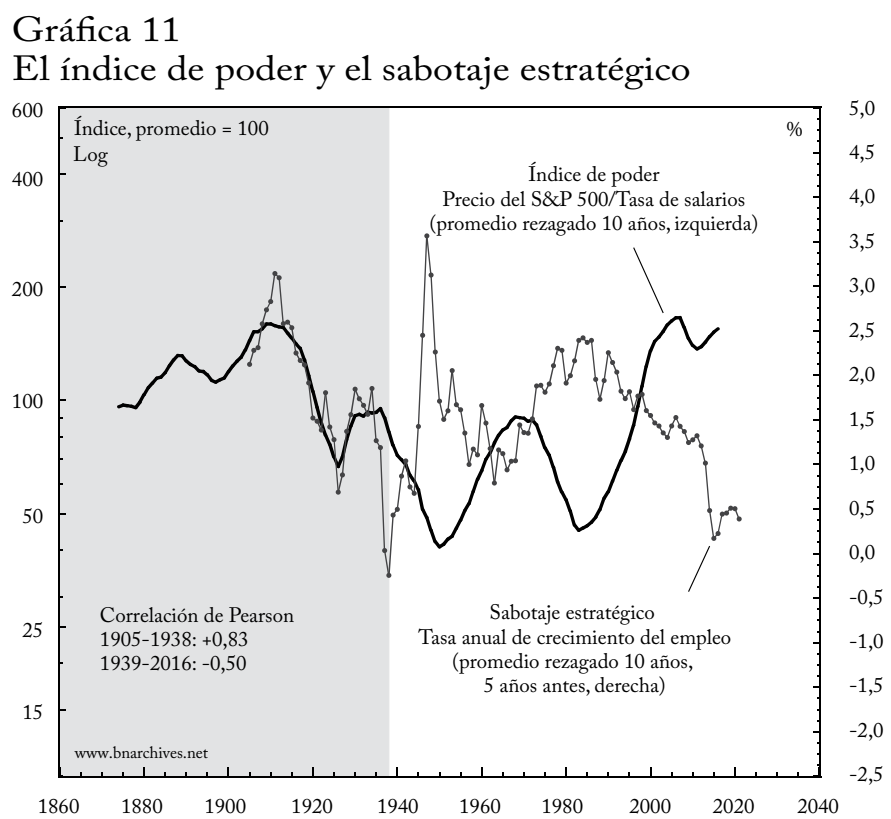

Nota: el precio de S\&P 500 empalma las cuatro subseries siguientes: una combinación de series de acciones de bancos, seguros y ferrocarriles ponderada por GFD (1820-1870), el índice Cowles/ Standard and Poor Composite (1871-1925), el índice 90-stock Composite (1926-1956) y el índice S\&P 500 (desde 1957 hasta hoy). La tasa de salarios empalma salarios por hora de trabajadores en la producción manufacturera hasta 1946 con salarios por hora de trabajadores del sector no agrícola desde 1947 en adelante. El área sombreada indica correlación positiva. Los últimos puntos de datos son 2016 para el índice de poder y 2021 para el sabotaje estratégico rezagado. Fuente: Precio del s\&P 500: GFD hasta 1900 (código de serie: sPXD) y GI desde 1901 en adelante (códigos de serie: JS\&PNS). La tasa de salarios por hora empalma las siguientes series: Historical Statistics of the United States, Millennial Edition Online: salarios por hora en manufacturas, todos los oficios, 1865-1889 (código de serie: Ba4290), salario por hora en la manufactura, todas las industrias, 1890-1913 (código de serie: Ba4299), salario semanal de los trabajadores en la producción de manufacturas, 1914-1918 (código de serie: Ba4362), salario por hora de los trabajadores en la producción de manufacturas, 1919-1938 (código de serie: Ba4361); GI: salarios promedio por hora de los trabajadores en la producción de manufacturas, 1939-1946 (código de serie: AHPMFNs); Conference Board a través de GI: remuneración promedio por hora de todos los empleados del sector no agrícola (código de serie: JRwsSNFE). El empleo hasta 1947 se tomó de Historical Statistics of the United States, Millennial Edition Online (código de serie: CivilianLaborForce_Employed_Total_Ba471_Thousand) y desde 1948 de u.s. Department of Labour a través de GI (promedio anual de la serie mensual, código de serie: ENs@Us).

crecimiento del empleo es una proxy inversa del sabotaje estratégico: es una de las métricas cruciales del bienestar y de la sensación de seguridad de la población, de modo que reducir esta proxy es un saboteo estratégico contra la mayoría de la gente ${ }^{25}$.

${ }^{25}$ Aunque la tasa de crecimiento del empleo invertida es central, no es la única forma de sabotaje (ver la nota 24). Muchos otros procesos sirven para socavar el bienestar y la seguridad de la población -aunque incorporarlos en nuestro indicador podría acabar siendo una espada de doble filo. Así refinen el análisis, 


\section{Reversión de la pauta social}

E1 aspecto sobresaliente en la gráfica es la notable reversión de la relación entre los dos índices en 1939: hasta ese año, el crecimiento del empleo y el índice de poder tenían una correlación positiva; y luego, de repente, como si alguien hubiese alterado la pauta social, la relación se tornó negativa.

¿Cómo fue posible esa reversión súbita? La respuesta requiere más investigación de la que podemos ofrecer aquí, pero esbocemos nuestra reflexión inicial al respecto. Recordemos que en los años treinta se experimentó un $\mathrm{PMB}$, y que esta se resolvió en últimas creordenando el modo de poder. El principal rasgo de ese creordenamiento fue el ascenso del Estado de bienestar-guerra keynesiano. Uno de los pilares clave del keynesianismo era la política contracíclica discrecional; para nuestro propósito, la política monetaria contracíclica discrecional. En nuestra opinión, el drástico paso a ese tipo de política podría explicar por qué se invirtió de repente la correlación entre poder capitalizado y sabotaje estratégico.

\section{Crecimiento del empleo y política monetaria}

Examinemos esta hipótesis algo más de cerca. Hasta 1939, los índices de poder y de crecimiento del empleo estaban estrecha y positivamente correlacionados (recordemos que el crecimiento del empleo es una proxy inversa del sabotaje). Por dos razones. Primera, aunque el poder capitalizado y el temor sistémico estaban disminuyendo, aún eran relativamente altos, de modo que los cambios de precios de las acciones se acercaron bastante a los cambios de las ganancias corrientes y, por tanto, a los del empleo (los niveles de ganancias y de empleo se correlacionan positivamente). Segunda, puesto que no había política monetaria contracíclica, esta correlación positiva se mantuvo casi inalterada.

Pero después de 1939 los capitalistas comenzaron a esperar que la política del gobierno atenuara el ciclo, en parte mediante la política monetaria contracíclica. Y como el ciclo es impulsado por el crecimiento del empleo, esperaban que un mayor crecimiento del empleo produjera escasez de dinero, tasas de interés más altas y, por tanto, menor capitalización. Se tardó algún tiempo para que esta expectativa se materializara pero, como muestra la gráfica 12 , se cumplió a sí misma.

pueden llevar a que el indicador sea más complejo, de menor duración y de difícil aplicación a otros países.

Revista de Economía Institucional, vol. i9, N. ${ }^{\circ} 36$, Primer Semestre/2oi7, pp. il-56 
Gráfica 12

Crecimiento del empleo y tasa de interés

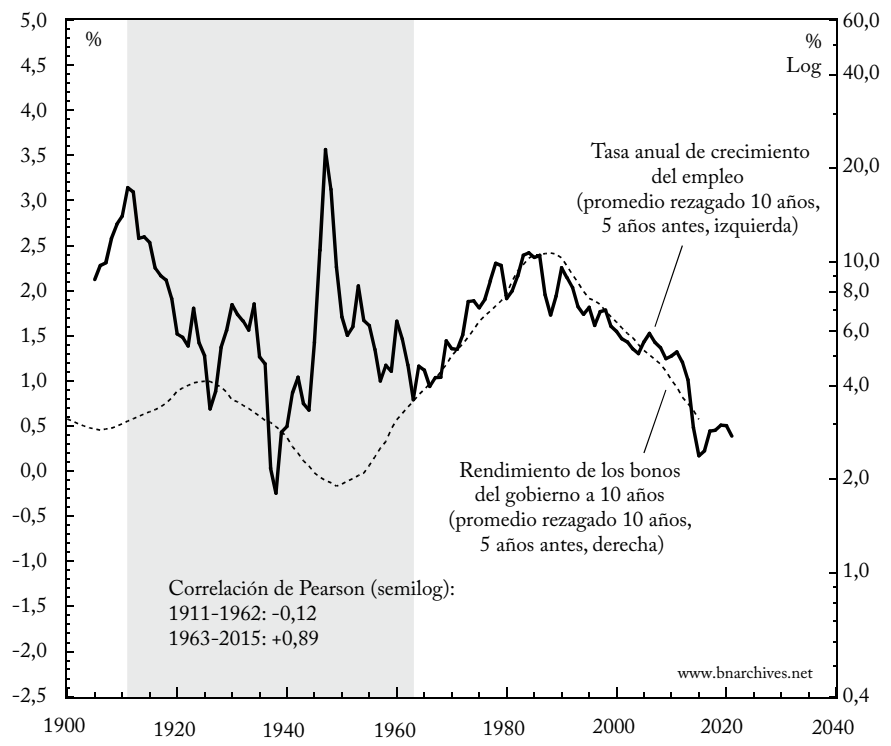

Nota: los últimos puntos de datos son 2015 para el rendimiento de los bonos del gobierno a diez años y 2021 para la tasa anual de crecimiento del empleo rezagada.

Fuente: empleo hasta 1947: Historical Statistics of the United States, Millennial Edition Online (código de serie: CivilianLaborForce_Employed_Total_Ba471_Thousand); desde 1948: U.S. Department of Labour a través de GI (promedio anual de la serie mensual, código de serie: ENS@US).El rendimiento de los bonos a diez años empalma datos de GFD hasta 1953 y de U.S. Federal Reserve Board a través de GI desde 1954 en adelante (código de serie: RMGB10Y@US).

La gráfica muestra dos series: la tasa anual de crecimiento del empleo (rezagada cinco años) en el eje izquierdo y el rendimiento de los bonos del gobierno a diez años en el de la derecha. Podemos ver que hasta mediados del siglo xx había poca o ninguna conexión entre las dos series (coeficiente de Pearson de -0,12). Pero desde comienzos de los sesenta, el crecimiento del empleo ha sido un predictor anticipado cinco años casi perfecto de las tasas de interés: cuanto más baja la tasa de crecimiento del empleo (y, por tanto, mayor el sabotaje estratégico), más baja la tasa de interés subsiguiente (con una correlación de Pearson de $+0,89)$. Y como unas bajas tasas de interés alientan la capitalización, se puede ver claramente cómo funcionó el sabotaje estratégico para alimentar el poder capitalizado.

\section{De un ciclo político de los negocios a un ciclo político CcP}

A comienzos de los años cuarenta, Michal Kalecki escribió un artículo importante en el que identificó lo que llamó “ciclo político de los ne- 
gocios" (Kalecki, 1943). Argumentó que el ciclo económico se había politizado profundamente de varias maneras, y que era impulsado cada vez más por la política del gobierno. Uno de sus principales argumentos era que la política expansionista aumenta el empleo y los salarios así como las ganancias y, por tanto, sirve a los intereses económicos tanto de los trabajadores como de los capitalistas. Pero la eficacia de dicha política demuestra que los gobiernos pueden sustituir a los capitalistas para generar y mantener la prosperidad, y esa demostración socava el interés político a largo plazo de los capitalistas en preservar su dominio de clase. Para Kalecki, esa contradicción entre intereses económicos y políticos de los capitalistas significa que, cuando se trata de mantener el pleno empleo, es posible que sacrifiquen su interés económico de mayores ganancias por el interés político de mantener su dominio.

Sin embargo -y aquí volvemos a nuestro modelo-, si pensamos en la acumulación de capital no como una actividad económica sino como la capitalización del poder, no hay ningún sacrificio. La consecuencia de una política más restrictiva puede ser un menor crecimiento del empleo y ganancias más bajas aquí y ahora; pero después, en circunstancias normales, esas consecuencias de corto plazo tienen poca o ninguna influencia en la capitalización prospectiva. Al mismo tiempo, si bien las consecuencias inmediatas de la política en términos de empleo y ganancias poco influyen en la capitalización, los instrumentos de política -en particular la tasa de interés- tienen un impacto enorme. Como indican las gráficas 11 y 12, el sabotaje intensificado a través del menor crecimiento del empleo se ha convertido en un indicador anticipado de tasas de interés más bajas, y tasas de interés más bajas aumentan el poder capitalizado.

Así, con lo que terminamos no es con un ciclo político de los negocios estrecho à la Kalecki sino con un ciclo político $C_{c} P$ más amplio. En este contexto, el gobierno no es una especie de distorsión exógena o una salida externa sino un componente integral de la capitalización de poder y de la regulación del sabotaje estratégico. Además, deja de existir un conflicto entre los "intereses políticos y económicos" de los capitalistas. Un mayor sabotaje estratégico los mantiene en el mando. $\mathrm{Y}$ aunque ese sabotaje socave las ganancias corrientes, permite bajar las tasas de interés, lo que es mucho más importante para capitalizar su poder prospectivo.

Por último, para cerrar nuestro modelo triangular, la gráfica 13 muestra la conexión entre sabotaje estratégico y temor sistémico. Esta gráfica representa el índice de temor sistémico en el eje izquierdo y el de sabotaje estratégico en el eje derecho. Igual que antes, ambas 
series se suavizan como promedios rezagados diez años, y el índice de sabotaje estratégico está rezagado cinco años. El eje derecho es invertido para que sea más fácil ver la correlación.

\section{Gráfica 13}

Sabotaje estratégico y temor sistémico

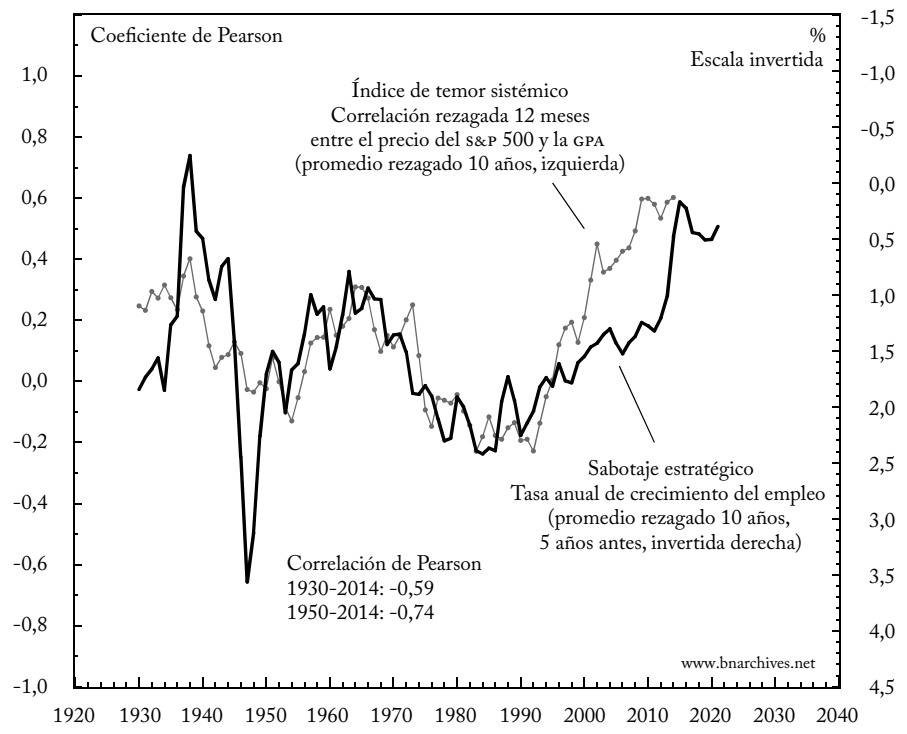

Nota: el índice de temor sistémico representa promedios anuales de la serie mensual de la gráfica 7 (definición allí). El precio de s\&P 500 empalma las cuatro subseries siguientes: una combinación de series de acciones de bancos, seguros y ferrocarriles ponderada por GFD (1820-1870), el índice Cowles/Standard and Poor Composite (1871-1925), el índice 90-stock Composite (1926-1956) y el índice s\&P 500 (desde 1957 hasta hoy). Los últimos puntos de datos son 2014 para el índice de temor y 2021 para el sabotaje estratégico aislado.

Fuente: empleo hasta 1947: Historical Statistics of the United States, Millennial Edition Online (código de serie: CivilianLaborForce_Employed_Total_Ba471_Thousand) y desde 1948: U.S. Department of Labour a través de GI (promedio anual de la serie mensual, código de serie: ENs@Us). Precio y GPA mensuales de s\&P 500: archivos de datos en línea de Robert J. Shiller [http://www.econ.yale.edu/ shiller data.xls], acceso del 20 de abril de 2016.

Ya sabemos que desde los años cuarenta un mayor sabotaje estratégico ha estado asociado, cinco años después, a un mayor poder capitalizado; pero, como ya señalamos, el sabotaje estratégico también suscita resistencia, y la resistencia aumenta el temor sistémico de los capitalistas; tal como se demuestra en la gráfica 13.

\section{CONCLUSIÓN}

Empezamos con el credo convencional de las tesis del desajuste, que: 1) supone que los inversionistas en acciones intentan continuamente 
fijarles precios que se ajusten a los fundamentos económicos subyacentes, 2) postula que rara vez o nunca lo logran, y 3) muestra que su presunto fracaso es un excelente predictor de los rendimientos futuros.

Luego pusimos de cabeza esa visión. Esbozamos un modelo CcP triangular del mercado de valores, mostrando que: 1) los índices de valoración del desajuste no son de hecho determinados por la utilidad ni por la productividad, sino por el poder capitalizado; 2) el poder capitalizado está entrelazado dialécticamente al temor sistémico, y 3) el poder capitalizado y el temor sistémico son impulsados por el sabotaje estratégico. Un corolario importante de este modelo es la noción de ciclo político CcP: la idea de que la política del gobierno, en la medida en que atiende al imperativo del poder capitalizado, favorece un bajo crecimiento del empleo para bajar las tasas de interés.

Y esa observación nos lleva al actual momento histórico. En los últimos treinta años, los capitalistas estadounidenses (y los que invierten en acciones de Estados Unidos) lograron aumentar su poder capitalizado con respecto al de la población, de récords mínimos a récords altos. En nuestra opinión, este aumento fue impulsado por dos procesos relacionados: 1) una redistribución del ingreso de los no capitalistas a los capitalistas, junto con la creciente convicción de que la desigualdad resultante se puede mantener e incluso aumentar en el futuro, y 2) el montaje de un sabotaje estratégico, en forma de menor crecimiento del empleo. En términos de la ecuación 2, el primer proceso significa un coeficiente de exageración $E$ más alto con respecto al valor de $m$. El segundo proceso tuvo doble impacto: por un lado, apoyó el primer proceso restringiendo los salarios y elevando las ganancias; por otro lado, hizo posible una política monetaria más flexible y tasas de interés más bajas, ayudando así a reducir la tasa normal de rendimiento tnr (en este periodo no hubo un descenso visible de la volatilidad de las ganancias, de modo que es difícil sacar conclusiones significativas sobre la percepción del riesgo).

Estos dos procesos fueron a su vez respaldados por un gran creordenamiento del modo de poder. Luego del рмв de 1968-1981, el capital se transnacionalizó progresivamente, restando poder a la población local, reduciendo las tasas de impuestos corporativas y personales de los individuos con activos netos elevados, capturando la política macroeconómica para fines capitalizados y atrayendo-forzando a los fondos de pensiones y a los activos públicos a participar en el mercado de valores, entre otras consecuencias. Pero ningún resorte se puede estirar indefinidamente. La redistribución impulsada por el conflicto y las bajas tasas de interés acercaron el poder capitalizado a su asíntota 
histórica, y este acercamiento significa que Estados Unidos -y quizá todo el mundo- hoy enfrenta una encrucijada histórica.

Mirando hacia adelante, podemos ver dos trayectorias posibles. $\mathrm{La}$ menos probable es alguna versión de El talón de hierro, de Jack London (1907), en la que la clase dirigente de Estados Unidos quebrante su asíntota histórica imponiendo un modo de poder mucho más severo que el que prevaleció en los dos últimos siglos. Para sostener ese nuevo modo de poder, los gobernantes tendrían que redistribuir el ingreso aún más en su favor, a nivel nacional y/o global, provocando niveles de desigualdad sin precedentes históricos. Además, y de modo crucial, tendrían que promover esta mayor desigualdad como la "nueva normalidad" (es decir, aumentar $m$ en la ecuación 2) y convencer a los inversionistas de que esa mayor desigualdad está para quedarse (para evitar que el coeficiente $E$ se desplome). Y mientras hacen todo eso, también tendrían que mantener bajas tasas de intereses y una baja volatilidad de las ganancias para evitar que la tasa de descuento aumente notablemente; una tarea formidable en un mundo marcado por mayor sabotaje, intensificación de la violencia y, por tanto, mayor inestabilidad.

La otra posibilidad, en nuestra opinión más probable, es que la historia se repita y que, tarde o temprano, Estados Unidos sufra otro рмв. Ahora bien, si el pasado ofrece alguna guía, salir de ese Рмв requeriría un gran creordenamiento del capitalismo, nacional y global, incluido el del papel de los gobiernos en el proceso de capitalización. $\mathrm{Y}$ aquí llegamos a nuestro punto final, quizá el más importante.

En caso de ocurrir, es posible que ese último creordenamiento trastorne el dogma dominante, y que ese trastorno abra un breve espacio histórico para alternativas críticas: nuevas teorías, nuevos experimentos de planeación pública y propuestas radicales para abolir el poder capitalizado en favor de la democracia directa y la autonomía (para nuestra modesta propuesta sobre este tema, ver Debailleul, Bichler y Nitzan, 2016). Sin embargo, para que estas teorías, estos experimentos y estas políticas alternativas tengan aceptación, deben trascender la fractura convencional del capitalismo. Deben superar las anticuadas nociones de que el capitalismo es un modo de producción y consumo contabilizado en útiles o tiempo de trabajo abstracto socialmente necesario; de que la política es distinta de "distorsionar/apoyar" la economía, según sea el caso; y de que las finanzas son de algún modo un reflejo burdo de la economía "real" subyacente. Apegarse a estas preconcepciones es encerrarse en la mentalidad capitalista. Y si seguimos encerrados en esta mentalidad, nos veremos condenados, 
una vez el рмв llegue y se vaya, a una nueva versión, creordenada, del mismo sistema capitalista.

\section{REFERENCIAS BIBLIOGRÁFICAS}

La mayoría de las publicaciones relacionadas con el CcP se consiguen gratuitamente en The Bichler E Nitzan Archives (http://bnarchives.net) y Capital as Power (http://capitalaspower.com).

1. Aitmatov, C. The day lasts more than a hundred years, trad. de J. French y prólogo de C. Clark, Bloomington, In, Indiana University Press, 1983.

2. New York Times. "Fisher sees stocks permanently high. Yale economist tells purchasing agents increased earnings justify rise", 16 de octubre de 1929.

3. Bichler, S. y J. Nitzan. "Contours of crisis: Plus ça change, plus c'est pareil?”, Dollars E Sense, 29 de diciembre de 2008.

4. Bichler, S. y J. Nitzan. "Contours of crisis II: Fiction and reality", Dollars E Sense, 28 de abril de 2009.

5. Bichler, S. y J. Nitzan. "Systemic fear, modern finance and the future of capitalism”, monografía, Jerusalén y Montreal, julio de 2010, pp. 1-42.

6. Bichler, S. y J. Nitzan. "The asymptotes of power", Real-World Economics Review 60, 2012a, pp. 18-53.

7. Bichler, S. y J. Nitzan. "Capital as power: Toward A new cosmology of capitalism", Real-World Economics Review 61, 2012b, pp. 65-84.

8. Bichler, S. y J. Nitzan. "No way out: Crime, punishment and the limits to power", Crime, Law and Social Change 61, 2014, pp. 251-271.

9. Bichler, S. y J. Nitzan. "Capital accumulation: Fiction and reality", Real-World Economics Review 72, 2015a, pp. 47-78. Traducido al español como "Acumulación de capital: ficción y realidad", Revista de Economia Institucional 17, 33, 2015, pp. 45-71.

10. Bichler, S. y J. Nitzan. "The CcP Project: Past, present, future", working papers on capital as power, 4 de diciembre de 2015b, pp. 1-29.

11. Bichler, S. y J. Nitzan. The scientist and the church, World Economics Association Books, WEA, 2015c.

12. Castoriadis, C. "Value, equality, justice, politics: From Marx to Aristotle and from Aristotle to ourselves", trad. del francés de C. Soper y M. Ryle, Crossroads in the Labyrinth, Brighton, The Harvester Press, 1984, pp. 260-339.

13. Castoriadis, C. "Power, politics, autonomy", D. A. Curtis, ed., Philosophy, politics, autonomy. Essays in political philosophy, Nueva York y Oxford, Oxford University Press, 1991, pp. 143-174.

14. Cochrane, D. T. "Who has the power? China's commodity use and the Canadian mining Business", Cuarto Foro sobre Capital como Poder "Ampliando la visión", Toronto, Universidad de York, 28-30 de septiembre de 2016.

15. Damodaran, $A$. The little book of valuation. How to value a company, pick a stock, and profit, Hoboken, nj, Wiley E Sons, 2011.

16. Damodaran, $A$. Investment valuation. Tools and techniques for determining the value of any asset, 3. ${ }^{a}$ ed., Hoboken, nj, Wiley E Sons, 2012. 
17. Debailleul, C.; S. Bichler y J. Nitzan. "Theory and praxis, theory and practice, practical theory", working papers on capital as power, febrero de 2016, pp. 1-13.

18. Fisher, I. Mathematical investigations in the theory of value and price. Appreciation and interest [1892], Nueva York, A. M. Kelley, 1965.

19. Fisher, I. "What is capital?", The Economic Journal 6, 24, 1896, pp. 509-534.

20. Fisher, I. The rate of interest. Its nature, determination and relation to economic phenomena, Nueva York, Macmillan, 1907.

21. Gittelsohn, J. "Gross trying to short credit to reverse decades of instinct", Bloomberg, 26 de mayo de 2016.

22. Glassman, J. C. y C. A. Hassett. Dow 36,000, Nueva York, Times Business, 1999.

23. Harcourt, G. C. "Some Cambridge controversies in the theory of capital", Journal of Economic Literature 7, 2, 1969, pp. 369-405.

24. Harcourt, G. C. Some Cambridge controversies in the theory of capital, Cambridge, Cambridge University Press, 1972.

25. Hegel, G. W. The phenomenology of mind [1807], trad. y notas de J. B. Baillie, Londres y Nueva York, Allen \& Unwin, 1971.

26. Hobbes, T. Leviathan [1691], A. Martinich, ed., Peterborough, Ont., Broadview Press, 2002.

27. Hunt, E. C. y M. Lautzenheiser. History of economic thought. A critical perspective, 3. ${ }^{\mathrm{a}}$ ed., Armonk, NY, M. E. Sharpe, 2011.

28. Hussman, J. Hussman investment research and insight 1, 2, 3 de octubre de 2000.

29. Hussman, J. "The 'new era' is an old story (and introducing market Cap/via)", Hussman Funds Weekly Market Comment, 18 de mayo de 2015a.

30. Hussman, J. "Rarefied air: Valuations and subsequent market returns", Hussman Funds Weekly Market Comment, 30 de noviembre de 2015b.

31. Hussman, J. "Far beyond double", Hussman Funds Weekly Market Comment, 31 de octubre de 2016.

32. Kalecki, M. "Political aspects of full employment" [1943], Selected essays on the dynamics of the capitalist economy. 1933-1970, Cambridge, Cambridge University Press, 1971, pp. 138-145.

33. Kliman, A.; S. Bichler y J. Nitzan. "Systemic crisis, systemic fear: An exchange”, número especial sobre 'crisis', Journal of Critical Globalization Studies 4, 2011, pp. 61-118.

34. London, J. The iron heel [1907], Nueva York, Hill and Wangm, 1957.

35. Malik, S. "The ontology of finance: Price, power, and the Arkhederivative”, R. Mackay, ed., Collapse, vol. viı, "Casino Real”, Falmouth, uk, Urbanomic, 2014, pp. 629-811.

36. Malik, S. y A. Phillips. "Tainted love: Art's ethos and capitalization”, M. Lind y O. Velthuis, eds., Contemporary art and its commercial markets. $A$ report on current conditions and future scenarios, Berlín, Sternberg Press, 2012, pp. 209-240.

37. Martin, U. "Rational control and the magma of reality", presentado en la conferencia anual de la Eastern Economic Association celebrada en Filadelfia, 26-28 de febrero de 2010. 
38. McKinsey \& Co., T. Koller, R. Dobbs y B. Huyett. Value. The four cornerstones of corporate finance, Hoboken, NJ, Wiley \& Sons, 2011.

39. McKinsey \& Co., T. Koller, M. E. Goedhart y D. Wessels. Valuation. Measuring and managing the value of companies, Hoboken, NJ, Wiley \& Sons, 2011.

40. McKinsey \& Co., R. Dobbs, A. Madgavkar et al. "Poorer than their parents? Flat or falling incomes in advanced economies", McKinsey Global Institute, julio de 2016, pp. 1-99.

41. Nitzan, J. "Price and quantity measurements: Theoretical biases in empirical procedures", working paper 14/1989, Department of Economics, McGill University, Montreal, 1989, pp. 1-24.

42. Nitzan, J. "Inflation as restructuring. A theoretical and empirical account of the U.S. experience", tesis de doctorado, Departamento de Economía, McGill University, 1992.

43. Nitzan, J. y S. Bichler. Capital as power. A study of order and creorder, Nueva York y Londres, Routledge, 2009a.

44. Nitzan, J. y S. Bichler. "Contours of crisis III: Systemic fear and forward-looking finance, Dollars $\xi$ Sense, 12 de junio de 2009b.

45. Nitzan, J. y S. Bichler. "Can capitalists afford recovery? Three views on economic policy in times of crisis", Review of Capital as Power 1, 1, pp. 110-155.

46. Ostry, J. D.; L. Parkash y D. Furceri. “Neoliberalism: Oversold?”, Finance and Development 53, 2 2016, pp. 38-41.

47. Piketty, T. Capital in the Twenty-First Century, A. Goldhammer, trad., Cambridge, Mass., y Londres, The Belknap Press of Harvard University Press, 2014.

48. Reinhart, C. M. y C. S. Rogoff. This time is different. Eight centuries of financial folly, Princeton, Princeton University Press, 2009.

49. Shiller, R. J. Irrational exuberance, Princeton, NJ, Princeton University Press, 2000.

50. Singh, S. Big bang. The most important scientific discovery of all time and why you need to know about it, Londres y Nueva York, Fourth Estate, 2004.

51. Veblen, T. The theory of business enterprise [1904], Clifton, NJ, A. M. Kelley, 1975.

52. Veblen, T. Absentee ownership and business enterprise in recent times. The case of America [1923], Introducción de R. Leckachman, Boston, Beacon Press, 1967.

53. Zweig, J. "Be inversely emotional, not unemotional", The Wall Street Journal, 26 de mayo de 2009, p. 28. 